Canadian

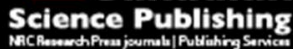

Canadian Geotechnical Journal Revue canadienne de géotechnique

\title{
Work input analysis for soils with double porosity and application to the hydro-mechanical modeling of unsaturated expansive clays
}

\begin{tabular}{|r|l|}
\hline Journal: & Canadian Geotechnical Journal \\
\hline Manuscript ID & cgj-2015-0574.R1 \\
\hline Manuscript Type: & Article \\
\hline Date Submitted by the Author: & $29-$ Mar-2016 \\
\hline Complete List of Authors: & $\begin{array}{l}\text { Li, Jian; State Key Laboratory of Geomechanics and Geotechnical } \\
\text { Engineering, Institute of Rock and Soil mechanics, Chinese Academy of } \\
\text { Sciences } \\
\text { Yin, Zhen-Yu; Research Institute in Civil and Mechanical Engineering, GeM } \\
\text { UMR CNRS 6183, Ecole centrale de Nantes } \\
\text { Cui, Yu-Jun; ENPC, Laboratoire NAVIER } \\
\text { Hicher, Pierre-Yves; Research Institute in Civil and Mechanical Engineering, } \\
\text { GeM UMR CNRS 6183, Ecole Centrale de Nantes }\end{array}$ \\
\hline Keyword: & $\begin{array}{l}\text { Double porosity, unsaturated expansive clay, work-conjugate variables, } \\
\text { constitutive relation, capillary hysteresis }\end{array}$ \\
\hline
\end{tabular}




\title{
Work input analysis for soils with double porosity and application to the hydro-mechanical modeling of unsaturated expansive clays
}

\author{
Jian $\mathrm{LI}^{1,2}$, Zhen-Yu YIN ${ }^{2,3, *}$, Yujun $\mathrm{CUI}^{3,4}$, Pierre-Yves HICHER ${ }^{2}$
}

\begin{abstract}
Affiliation:
${ }^{1}$ School of Civil Engineering, Beijing Jiaotong University, Beijing 100044, P. R. China

${ }^{2}$ LUNAM University, Ecole Centrale de Nantes, UMR CNRS GeM, BP 92101, 44321 Nantes

Cedex 3, France

${ }^{3}$ Key Laboratory of Geotechnical and Underground Engineering of Ministry of Education, Tongji University, Shanghai 200092, P. R. China

${ }^{4}$ Ecole des Ponts ParisTech, Laboratoire Navier/CERMES, 6 et 8 avenue Blaise Pascal, 77455 Marne La Vallée, France

* Corresponding author: Dr. Zhen-Yu YIN, Tel. +33 240371588, Fax +33 240372535, Email: zhenyu.yin@gmail.com
\end{abstract}




\title{
Title: Work input analysis for soils with double porosity and application to the hydro-mechanical modeling of unsaturated expansive clays
}

Authors: Jian LI; Zhen-Yu YIN; Yujun CUI; Pierre-Yves HICHER

\begin{abstract}
:
A mechanical approach for unsaturated expansive soils considering double porosity has been developed based on the porous media theory. In this approach, the adsorbed and the capillary water, as well as the micro and macro pores, are two distinct phases. An inter-aggregate stress considered as the work-conjugate of the macrostructural strain increment has been defined. Both physico-chemical and capillary effects of the pore water have been introduced at the macroscopic level. Other work-conjugate variables relevant for the constitutive modeling of double-porosity unsaturated media have also been identified, consisting of the modified suction as conjugate of the increment of the macrostructural degree of saturation and the microstructural effective stress as conjugate of the microstructural volumetric strain increment. A hydro-mechanical model for unsaturated expansive clays taking into account the interaction between the micro and the macro structures in expansive clays can thus be built. Based on the bounding surface concept, an anisotropic loading-collapse yield surface has been introduced to reproduce the three-dimensional mechanical behavior. In order to analyze the model capabilities, two series of laboratory tests consisting of multiple wetting and drying cycle tests on Boom clay and triaxial tests on ZY expansive clay were simulated. The comparisons between numerical and experimental results show that the model can reproduce with reasonable accuracy the mechanical behavior and the water retention characteristic of unsaturated expansive clays.
\end{abstract}

\section{Keywords:}

double porosity, unsaturated expansive clay, work-conjugate variables, constitutive relation, capillary hysteresis, anisotropy 


\section{Introduction}

Geomaterials such as fissured rocks (Barenblatt et al. 1960), natural and compacted clays (Sridharan et al. 1971; Delage et al. 1982), and bentonite pellet mixtures (Hoffmann et al. 2007) have a pore size distribution with at least two dominant porosities, i.e., a double porosity. The two scales of porosity correspond to the micropores (e.g., matrix pores, intra-aggregate pores or intra-pellet pores) and macropores (fissures, inter-aggregate pores or inter-pellet pores). For expansive clays, the microstructure evolution under different loading conditions and wetting/drying paths has been studied extensively by mercury intrusion porosimetry (e.g., Delage and Lefebvre 1984; Hoffmann et al. 2007; Romero et al. 2011). These results show that the macrostructural deformation is strongly affected by the mechanical loading for aggregated clays, whereas the corresponding change in micropores is smaller and mainly reversible. On the other hand, the micropores of an expansive clay can vary significantly during wetting or drying, accompanied by a reversible volumetric change of the aggregates. However, the macrostructural deformation is always irreversible upon wetting and drying cycles and depends on the initial dry density, the external applied stresses, the range of suction, etc. Thus, the different deformation characteristics of both the micro and macro structures lead to a complex hydro-mechanical behavior of unsaturated expansive clays, which in turn leads to real challenges for constitutive modeling which can comprehensive depict these behavior.

To describe this complex hydro-mechanical behavior, the effects of the microstructural deformations need to be taken into account. The selection of appropriate stress variables for double-porosity media is the primary task. The currently proposed stress variables entail some 
deficiencies. For example, Khalili et al. (2005) suggested an effective stress expression for unsaturated porous media with a double porosity by considering the contribution of each fluid pressure within the pores and fissures. This effective stress was used to depict the total deformation of the porous media rather than the microstructural deformation. Borja and Koliji (2009) suggested a similar definition based on thermodynamic principles. On the other hand, based on the effective stress principle, Gens and Alonso (1992) and Mašín (2013) suggested a microstructural effective stress for modeling the deformation of the particle element, i.e., aggregate. Besides, based on the microstructural observations, Della Vecchia and Romero (2013) suggested an expression describing the aggregate size evolution with water content and void ratio. However, the selection of the stress variables in the latter two studies was not based on thermodynamic principles.

Elasto-plastic models with isotropic loading-collapse yield surfaces for expansive clays were suggested by Gens and Alonso (1992), Sheng et al. (2004), Chen (2007) and Sun and Sun (2012). Laboratory tests under compression with different stress ratios on Jossigny silty clay and Zaoyang (ZY) expansive clay by Cui and Delage (1996), Zhan and Ng (2006) and Chen (2007), respectively, showed that the yield surface should be anisotropic under a given suction value. The soil anisotropy can be inherent (caused by particle orientation during soil formation) or induced (caused by loading paths applied to the soil or other factors). It has been shown that incorporating the anisotropy in constitutive modeling can generally improve the predictive ability for saturated and unsaturated soils (e.g., Banerjee and Yousif 1986; Wheeler et al. 2003; Stropeit et al. 2008; D’Onza et al. 2011; Al-Sharrad and Gallipoli 2014). Therefore, it may also help to introduce the anisotropy into the constitutive modeling of 
expansive clays.

In this study, we have extended the work input approach to unsaturated expansive clays based on the porous media theory for materials with double porosity. Work-conjugate stress variables and strain increment variables relevant for the constitutive modeling of double-porosity unsaturated media are then identified. A novel hydro-mechanical constitutive model for unsaturated expansive soils is then formulated. An anisotropic yield surface based on the bounding surface concept is introduced to simulate the three-dimensional mechanical behavior of this type of materials. Laboratory tests on unsaturated compacted expansive clays consisting of multiple wetting and drying cycle tests on Boom clay and triaxial tests on ZY expansive clay are then simulated to analyze the model capability of reproducing the hydro-mechanical behavior of unsaturated expansive clays.

\section{Work input considering double porosity}

Baker and Frydman (2009) suggested a double porosity conceptual model for unsaturated expansive clays. In their model, the expansive clay is composed of four phases, i.e., aggregates (ag), capillary water (c), adsorbed water (ad) and air (a). The total surface of the aggregates is covered by adsorbed water, the capillary water being concentrated in the inter-aggregate pores, and air occupying the central portion of the inter-aggregate pores. At the microscopic level, the aggregate phase is made of two compositions, i.e., a solid matrix (i.e., clay platelets) and adsorbed water. This double porosity conceptual model has been adopted in this study to calculate the work input.

The power input to a representative elementary volume (REV) with a volume $V$ and a 
boundary area $A$ is the sum of the power input at the boundary and the power coming from gravitational forces:

$$
\begin{aligned}
& \int_{V} W \mathrm{~d} V=-\int_{A}\left[n_{M} \sum_{\alpha} S_{r}^{\alpha} u_{\alpha} v_{i}^{\alpha} \delta_{i j}+\left(1-n_{M}\right) s_{i j} v_{i}^{a g}\right] n_{j} \mathrm{~d} A \\
& \quad+\int_{V}\left[n_{M} \sum_{\alpha} S_{r}^{\alpha} \rho^{\alpha} v_{i}^{\alpha}+\left(1-n_{M}\right) \rho^{a g} v_{i}^{a g}\right] g_{i} \mathrm{~d} V, \quad \alpha=c, a d, a
\end{aligned}
$$

where the negative sign on the area integral arises from the convention of positive compression; $u^{\alpha}$ is the $\alpha$ phase pressure; $s_{i j}$ is the average stress in the aggregate phase with the similar definition as average stress for soil grains was adopted by Houlsby (1997) and Zhao et al. (2015); $n_{M}$ is the macroporosity defined as the ratio of the macropores over the total volume of REV; $S_{\alpha}$ is the macrostructural degree of saturation of the $\alpha$ phase defined as the ratio of the volume of the $\alpha$ phase over the volume of the macropores; $\rho^{a g}$ and $\rho^{\alpha}$ are the densities of the aggregate and the $\alpha$ phases, respectively; $n_{i}$ is the outward normal to the surface $A ; g_{i}$ is the gravitational acceleration vector; $v_{i}$ and $f_{i}^{\alpha}$ are the average velocities of the aggregate and the $\alpha$ phases, respectively; the seepage velocity of the $\alpha$ phase is defined by $w_{i}^{\alpha}=n_{M} S_{\alpha}\left(f_{i}^{\alpha}-v_{i}\right)$.

Based on the porous media theory and considering the above decomposition, the total stress in the soil can be obtained by (Houlsby 1997; Borja and Koliji 2009; Zhao et al. 2010):

$$
\sigma_{i j}=\sum_{\alpha}\left(n_{M} S_{r}^{\alpha} u_{\alpha} \delta_{i j}\right)+\left(1-n_{M}\right) s_{i j}
$$

And the overall soil density is given by:

$$
\rho=\sum_{\alpha}\left(n_{M} S_{r}^{\alpha} \rho^{\alpha}\right)+\left(1-n_{M}\right) \rho^{a g}
$$

Substituting Eqs. (2), (3) into Eq. (1) and applying the Gauss divergence theorem lead to:

(4) $\quad W=-\sum_{\alpha}\left(u_{\alpha, j}^{\prime} w_{j}^{\alpha}\right)-\sum_{\alpha}\left(u_{\alpha} w_{j, j}^{\alpha}\right)-\sigma_{i j} v_{i, j}$ 
where $u_{\alpha, j}^{\prime}$ is the excess pore pressure gradient in the $\alpha$ phase. Here, the integral signs on both sides of the equation are removed, and it is assumed that the total stress equilibrium is satisfied, i.e. $-\sigma_{i j, j}+\rho g_{i}=0$.

The mass conservation equations of aggregate, capillary water, adsorbed water and air phases can be expressed as:

(5)

$$
\left\{\begin{array}{l}
\frac{\partial\left[\left(1-n_{M}\right) \rho^{a g}\right]}{\partial t}+\operatorname{div}\left[\left(1-n_{M}\right) \rho^{a g} v_{i}\right]=c^{a g} \\
\frac{\partial\left(n_{M} S_{r}^{c} \rho^{c}\right)}{\partial t}+\operatorname{div}\left(n_{M} S_{r}^{c} \rho^{c} f_{i}^{c}\right)=c^{c} \\
\frac{\partial\left(n_{M} S_{r}^{a d} \rho^{a d}\right)}{\partial t}+\operatorname{div}\left(n_{M} S_{r}^{a d} \rho^{a d} f_{i}^{a d}\right)=c^{a d} \\
\frac{\partial\left(n_{M} S_{r}^{a} \rho^{a}\right)}{\partial t}+\operatorname{div}\left(n_{M} S_{r}^{a} \rho^{a} f_{i}^{a}\right)=0
\end{array}\right.
$$

where $c^{\alpha}$ is the mass exchange rate of the $\alpha$ phase with the other phases, and the value of $c^{\alpha}$ is positive when the $\alpha$ phase obtains additional mass from other phases. At the microscopic level, the aggregate phase is made of the solid matrix (i.e., clay platelets) and the adsorbed water. Therefore, $c^{a d}$ can be decomposed into $c_{a g}^{a d}$ and $c_{c}^{a d}$, which are the rates of mass exchange of the adsorbed water phase in macropores with the aggregate phase and the capillary water phase, respectively. The equation $c^{c}+c^{a d}+c^{a g}=0$ needs to be satisfied.

Substituting the seepage velocity of the $\alpha$ phase into Eq. (5) and noting $v_{i, i}=-\dot{\varepsilon}_{v}$ lead to:

(6)

$$
\left\{\begin{array}{l}
w_{i, i}^{c}=S_{r}^{c} \dot{\varepsilon}_{v}-n_{M} \dot{S}_{r}^{c}-S_{r}^{c}\left(1-n_{M}\right) \frac{\dot{\rho}^{a g}}{\rho^{a g}}+S_{r}^{c} \frac{c^{a g}}{\rho^{a g}}+\frac{c^{c}}{\rho^{c}} \\
w_{i, i}^{a d}=S_{r}^{a d} \dot{\varepsilon}_{v}-n_{M} \dot{S}_{r}^{a d}-S_{r}^{a d}\left(1-n_{M}\right) \frac{\dot{\rho}^{a g}}{\rho^{a g}}+S_{r}^{a d} \frac{c^{a g}}{\rho^{a g}}+\frac{c^{a d}}{\rho^{a d}} \\
w_{i, i}^{a}=S_{r}^{a} \dot{\varepsilon}_{v}-n_{M} \dot{S}_{r}^{a}-S_{r}^{a}\left(1-n_{M}\right) \frac{\dot{\rho}^{a g}}{\rho^{a g}}+S_{r}^{a} \frac{c^{a g}}{\rho^{a g}}-n_{M} S^{a} \frac{\dot{\rho}^{a}}{\rho^{a}}
\end{array}\right.
$$


where $\dot{\varepsilon}_{v}$ is the total volumetric strain increment. Here, it is assumed that the spatial variations of $n_{M}$ and $S_{\alpha}$ are negligible (Houlsby 1997).

Based on the first equation of Eq. (5), the density change rate of the aggregate phase can be expressed as:

$$
\dot{\rho}^{a g}=\rho^{a g} \frac{\dot{n}_{M}}{1-n_{M}}+\frac{c^{a g}}{1-n_{M}}+\rho^{a g} \dot{\varepsilon}_{v}
$$

Because the macroporosity is defined by $n_{M}=e_{M} /(1+e)$, its increment can be obtained by:

$$
\text { (8) } \quad \dot{n}_{M}=\frac{\dot{e}_{M}}{1+e}-n_{M} \frac{\dot{e}}{1+e}=-\dot{\varepsilon}_{v}^{M}+n_{M} \dot{\varepsilon}_{v}
$$

where $\dot{\varepsilon}_{v}$ is the sum of the macro and micro structural volumetric strain rates (corresponding to inter-aggregate macropores and intra-aggregate micropores), i.e., $\dot{\varepsilon}_{v}=\dot{\varepsilon}_{v}^{M}+\dot{\varepsilon}_{v}^{m} ; \dot{\varepsilon}_{v}^{M}$ is defined by $\dot{\varepsilon}_{v}^{M}=-\dot{e}_{M} /(1+e)$ and $\dot{\varepsilon}_{v}^{m}$ is defined by $\dot{\varepsilon}_{v}^{m}=-\dot{e}_{m} /(1+e)$; the macro void ratio $e_{M}$ is defined as the ratio of the volume of the macropores over solid volume; the micro void ratio $e_{m}$ is defined as the ratio of the volume of the micropores over the solid volume; the total void ratio $e$ is the sum of $e_{M}$ and $e_{m}$. Alternative definitions of macro void ratio and strain rates were adopted by Mašín (2013). Using these definitions, the expression of work input is deduced in Appendix A. Substituting Eq. (8) into Eq. (7) leads to:

(9) $\quad \dot{\rho}^{a g}=\frac{\rho^{a g} \dot{\mathcal{\varepsilon}}_{v}^{m}+c^{a g}}{1-n_{M}}$

Furthermore, the mass exchange between the aggregate and the adsorbed water phases leads to a microstructural volume change. Thus, the micro volumetric strain rate can be expressed as:

$$
\dot{\varepsilon}_{v}^{m}=-\frac{\dot{V}^{a g}}{V}=\frac{\left(c_{a g}^{a d} / \rho^{a d}\right) V}{V}=c_{a g}^{a d} / \rho^{a d}
$$


where $V^{a g}$ is the volume of the aggregates in the REV.

Substituting Eqs. (6), (9) and (10) into Eq. (4) gives the work input to unsaturated expansive soils considering double porosity as:

$$
\begin{aligned}
W= & -u_{c, j}^{\prime} w_{j}^{c}-u_{a d, j}^{\prime} w_{j}^{a d}-u_{a, j}^{\prime} w_{j}^{a}+\left(\sigma_{i j}-u_{c} S_{r}^{c} \delta_{i j}-u_{a d} S_{r}^{a d} \delta_{i j}-u_{a} S_{r}^{a} \delta_{i j}\right) \dot{\varepsilon}_{i j}^{M^{\prime}} \\
& -n_{M}\left(u_{a}-u_{c}\right) \dot{S}_{r}^{c}-n_{M}\left(u_{a}-u_{a d}\right) \dot{S}_{r}^{a d}-\left(u_{c}-u_{a d} \frac{\rho^{c}}{\rho^{a d}}\right) \frac{c^{c}}{\rho^{c}} \\
& +u_{a} n_{M} S^{a} \frac{\dot{\rho}^{a}}{\rho^{a}}+\left(p-u_{a d}\right) \dot{\varepsilon}_{v}^{m^{\prime}}
\end{aligned}
$$

where $\varepsilon_{i j}^{M}$ is the macrostructural strain tensor; $p$ is the total mean stress. The first three terms on the left side of the equation represents the work caused by the seepage of the pore fluid relative to the aggregate phase; the fourth term represents the work caused by the deformation of the macrostructure; the fifth and sixth terms represent the works caused by the change in the degree of saturation of the capillary water and adsorbed water phases in macropores, respectively; the seventh term represents the work caused by the mass exchange of the capillary water phase with the adsorbed water phase; the eighth term represents the work caused by the compression of the air phase; the ninth term represents the work caused by the deformation of the microstructure.

The interpretation of some key terms in Eq. (11) is as follows. Firstly, the fourth term in Eq. (11) implies that the stress variable work-conjugate of the macrostructural strain increment is $\sigma_{i j}^{*}=\left(\sigma_{i j}-u^{a} \delta_{i j}\right)+S_{r}^{c}\left(u^{a}-u^{c}\right) \delta_{i j}+S_{r}^{a d}\left(u^{a}-u^{a d}\right) \delta_{i j}$, which is termed as the inter-aggregate stress. Different from Bishop's stress, the additional term $S_{r}^{a d}\left(u^{a}-u^{a d}\right) \delta_{i j}$ in the inter-aggregate stress considers the physico-chemical effect between the absorbed water and the solid matrix. Note that a similar inter-particle stress variable considering the physico-chemical effect was proposed by Lu and Likos (2006) based on particle-scale 
equilibrium analyses. Secondly, the fifth and sixth terms imply that the stress variables work-conjugate of $\dot{S}_{r}^{c}$ and $\dot{S}_{r}^{a d}$ are $n_{M}\left(u_{a}-u_{c}\right)$ and $n_{M}\left(u_{a}-u_{a d}\right)$, respectively. These stress variables are similar to the modified suction proposed by Houlsby (1997). However, the water content change related to the adsorbed water phase has been separated from the capillary water phase in the macropores. Thirdly, the ninth term implies that the stress variable work-conjugate of the microstructural volumetric deformation is $\left(p-u_{a d}\right)$, which implies the effect of the external applied stresses and adsorbed water pressure on the size of the aggregates.

\section{Constitutive modeling}

\section{Choice of stress and strain variables}

Selecting stress and strain variables is the first step for establishing a constitutive model. On the basis of thermodynamics theory, the stress variables can be chosen from the expression of the input work. Based on the proposed input work expression for unsaturated expansive soils considering double porosity, several groups of work-conjugate variables have been chosen to develop an elasto-plastic constitutive model. In the derivation of the work input considering double porosity, the adsorbed water has been separated from the capillary water. Thus, it is necessary to obtain the adsorbed water pressure and the adsorbed water content within the soil. On the one hand, the pulsed NMR technique has been increasingly adopted to evaluate the content of adsorbed water and capillary water in geomaterials (Tian and Wei 2014). To our knowledge, however, the adsorbed water pressure cannot be measured directly, limiting the application of Eq. (11). Therefore, it has been assumed that the adsorbed water in macropores 
is part of the aggregates (Baker and Frydman 2009). Then, Eq. (11) can be simplified to:

$$
\begin{aligned}
W= & -u_{c, i}^{\prime} w_{i}^{c}-u_{a, i}^{\prime} w_{i}^{a}-u_{a d, i}^{\prime} w_{i}^{a d}+\left(\sigma_{i j}^{\prime}+s S_{r}^{M} \delta_{i j}\right) \dot{\varepsilon}_{i j}^{M} \\
& -n_{M} s \dot{S}_{r}^{M}+u_{a} n_{M} S_{r}^{a} \frac{\dot{\rho}^{a}}{\rho^{a}}+\left[p^{\prime}+\frac{\rho^{a d}}{\rho^{c}} s+u_{a}\left(1-\frac{\rho^{a d}}{\rho^{c}}\right)\right] \dot{\varepsilon}_{v}^{m}
\end{aligned}
$$

where $\sigma_{i j}^{*}$ is the modified inter-aggregate stress defined by $\sigma_{i j}^{*}=\sigma_{i j}^{\prime}+s S_{r}^{M} \delta_{i j} ; s^{*}$ is the modified suction defined by $s^{*}=n_{M} s ; s$ is the matric suction defined by $s=u^{a}-u^{c} ; S_{r}^{M}$ is the macrostructural degree of saturation (water volume in macropore over the macropore volume) which is equal to the "effective degree of saturation" $S_{r}^{e}$ by Alonso et al. (2010). The definition of $\sigma_{i j}^{*}$ is similar to Bishop's stress, and the effective stress parameter is $S_{r}^{M}$. Alonso et al. (2010) stated that the effective stress parameter of Bishop's stress should be chosen as the effective degree of saturation $S_{r}^{e}$, rather than the total degree of saturation for unsaturated clays. Furthermore, the adsorbed water in macropores has been assumed as part of the aggregates; thus, the physico-chemical effect in the inter-aggregate stress has been omitted.

According to the definition of the matric suction (Derjaguin et al. 1987; Tuller et al. 1999), the suction defined by $s=u^{a}-u^{c}$ in Eq. (12) is only the capillary part of the matric suction. Its adsorptive part has been ignored, which limits the range of application of Eq. (12). Therefore, this equation is appropriate when the value of the pore water potential is greater than that corresponding to the cavitation of the capillary water. At equilibrium state, the potential of capillary water in the macropores is equal to the potential of adsorbed water in the micropores. In this pore water potential range, the macropores are unsaturated and filled by capillary water and air, and the capillary potential is always equal to $-\left(u^{a}-u^{c}\right)$. The 
cavitation tension of fined-grained soils is usually higher than $100 \mathrm{kPa}$. For example, the cavitation tension of Barcelona silt is equal to 1-2 MPa (Gens et al. 1995). When the system is subjected to drying by exposing it to an external water potential equaled to or lower than that corresponding to the cavitation of the capillary water, cavitation of the capillary water in the macropores occurs. The above mechanism was broadly discussed by Romero et al. (1999) and Baker and Frydman (2009).

Under the triaxial condition, the stress variables and work-conjugate strain increments are chosen as:

$$
\left[p^{*}, q, s^{*}, \hat{p}\right]^{T},\left[d \varepsilon_{v}^{M}, d \varepsilon_{s}^{M}, d S_{r}^{M}, d \varepsilon_{v}^{m}\right]^{T}
$$

where $p^{*}$ is the mean inter-aggregate stress defined by $p^{*}=p^{\prime}+s S_{r}^{M} ; p^{\prime}$ is the net mean stress; $q$ is the deviator stress; $\hat{p}$ is the microstructural effective stress defined by $\hat{p}=p^{\prime}+\chi s$ with $\chi=\rho^{a d} / \rho^{c} \approx 1.3 ; d \varepsilon_{s}^{M}$ is the shear strain increment. The stress variable work-conjugate to the microstructural volumetric deformation has been modified. Because the proposed model is an incremental generalized stress-strain relationship, the constant part of the microstructural effective stress omitted. The simplified definition of $\hat{p}$ is similar to that proposed by Gens and Alonso (1992) except for the constant coefficient in the second term. Based on an extensive experimental database of different bentonites available in published literature, Mašín and Khalili (2015) pointed out that both of loading and change in pore water pressure affect the mechanical behaviour of aggregates. The simplified definition of $\hat{p}$ is consistent with the above conclusion.

\section{Application of the bounding surface concept}


In order to account for the deformation and water retention behavior under triaxial compression, a hydro-mechanical model for unsaturated expansive clay is being suggested. Three groups of bounding surfaces have been built in order to represent the mechanical and water retention behavior. The first is the loading-collapse (LC) bounding surface describing the irreversible contraction deformation caused by the increase of the inter-aggregate stress and the decrease of the suction. The second is the microstructural stress increase and decrease (MI and MD) bounding surfaces suggested to describe the macrostructural deformation caused by the microstructural volumetric strain as first proposed by Gens and Alonso (1992). The third is the suction increase and decrease (SI and SD) bounding surfaces controlled by the variation of the macrostructural degree of saturation.

\section{LC bounding surface}

Laboratory tests under triaxial compression with different stress ratios were carried out by Cui and Delage (1996), Zhan and Ng (2006) and Chen (2007) on various types of unsaturated soils, i.e., Jossigny silty clay and Zaoyang (ZY) expansive clay respectively, at given suction values. As shown in Figure 1, the initial LC yield surfaces in the $\left(p^{\prime}: q\right)$ plane at different suctions can be plotted as a group of rotating ellipses under triaxial condition. Thus, using an expression modified from the one proposed by Dafalias (1982) and Wheeler et al. (2003), the formulation of the LC yield curve is expressed as (see Figure 2):

$$
f_{L C}=\left[\bar{q}-\alpha\left(\bar{p}^{*}+p_{s}^{*}\right)\right]^{2}-\left(M^{2}-\alpha^{2}\right)\left(\bar{p}_{m}^{*}-\bar{p}^{*}\right)\left(\bar{p}^{*}+p_{s}^{*}\right)=0
$$

where the stress point $\left(\bar{p}^{*}, \bar{q}\right)$ lies on the LC bounding surface and is defined according to a radial mapping rule so that it has the same stress ratio as the current stress point, defined by 
$\eta^{*}=\bar{q} /\left(\bar{p}^{*}+p_{s}^{*}\right)=q /\left(p^{*}+p_{s}^{*}\right) ; \quad p_{s}^{*}$ represents the tensile strength with $p_{s}^{*}=\mu / M ; \mu$ is the intercept of the critical state line in the $\left(p^{*}: q\right)$ plane; $M$ is the slope of the critical state line in the $\left(p^{*}: q\right)$ plane; $\bar{p}_{m}^{*}$ and $\alpha$ are the hardening parameters defining the size and the inclination of the LC bounding surface in the $\left(p^{*}: q\right)$ plane.

The maximum inter-aggregate stresses on the LC bounding surface at a given suction, $\bar{p}_{m}^{*}(s)$, can be determined by the expression of the normal consolidation line at different suction values (Wheeler and Sivakumar, 1995):

(15) $\quad \bar{p}_{m}^{*}(s)=\bar{p}_{m}^{*}(0)^{\frac{\lambda(0)-\kappa}{\lambda(s)-\kappa}} \exp \left[\frac{N(s)-N(0)}{\lambda(s)-\kappa}\right]$

where $\lambda(s)$ and $N(s)$ are the slope and intercept of the normal consolidation line in the $\left(p^{*}: q\right)$ plane.

MI and MD bounding surface

The expression of the MI and MD bounding surfaces are (see Figure 3) (Gens and Alonso 1992):

$$
\begin{cases}f_{M I}=\hat{p}-\hat{p}_{I}=0 & \hat{p}>0 \\ f_{M D}=\hat{p}_{D}-\hat{p}=0 & \hat{p}<0\end{cases}
$$

where $\hat{p}_{I}$ and $\hat{p}_{D}$ are the hardening parameters controlling the position of the MI and MD bounding surfaces in the $\left(p^{\prime}: s\right)$ plane, respectively. According to the definition of the microstructural effective stress, the MI and MD bounding surfaces are inclined in the $\left(p^{\prime}: s\right)$ plane. The slopes of the yield lines are related to the density ratio between adsorbed and capillary water, different from the one proposed by Gens and Alonso (1992).

\section{SI and SD bounding surfaces}


The water retention behavior in unsaturated soils could not be satisfactorily modeled within classical elasto-plasticity due to the non-existence of a pure elastic domain in the zone delimited by the main wetting and drying curves of SWRC. Several authors have modeled the water retention behavior using bounding surface plasticity (Li 2005; Liu and Muraleetharan 2006; Raveendiraraj 2009). In the suggested model, the bounding surface concept has been applied to SWRC. The SI and SD bounding surfaces are expressed as (see Figure 4):

$$
\begin{cases}f_{S I}=s^{*}-s_{I}^{*}=0 & s^{*}>0 \\ f_{S D}=s_{D}^{*}-s^{*}=0 & s^{*}<0\end{cases}
$$

where $s_{I}^{*}$ and $s_{D}^{*}$ are the hardening parameters controlling the position of the SI and SD bounding surfaces, respectively, in the $\left(p^{\prime}: s^{*}\right)$ plane.

\section{Stress-strain relationship}

It is assumed that the total volumetric deformation of an expansive clay is composed of the macrostructural and aggregate size changes, the shear strain of the aggregates being ignored. In addition, it is assumed that the micropores are saturated with adsorbed water; thus the value of the total degree of saturation can be obtained from the macrostructural degree of saturation. The generalized total strains can then be defined by:

$$
\left\{\begin{array}{l}
\varepsilon_{v}=\varepsilon_{v}^{M}+\varepsilon_{v}^{m} \\
\varepsilon_{s}=\varepsilon_{s}^{M} \\
S_{r}=\left(e_{M} / e\right) S_{r}^{M}+\left(e_{m} / e\right)
\end{array}\right.
$$

where $\varepsilon_{s}$ is the total shear strain; $S_{r}$ is the total degree of saturation. According to the method proposed by Alonso and Gens (1992), the plastic macrostructural volumetric strain is decomposed into two parts: The first one represents the contracted or collapse deformation caused by the loading or wetting; the second one represents the macrostructural deformation 
caused by the coupling effect of aggregates swelling or shrinkage. Then, the strain increments can be expressed as:

$$
\left\{\begin{array}{l}
\mathrm{d} \varepsilon_{v}^{M}=\mathrm{d} \varepsilon_{v}^{M e}+\mathrm{d} \varepsilon_{v(L C)}^{M p}+\mathrm{d} \varepsilon_{v(M I / M D)}^{M p} \\
\mathrm{~d} \varepsilon_{s}^{M}=\mathrm{d} \varepsilon_{s}^{M e}+\mathrm{d} \varepsilon_{s(L C)}^{M p}+\mathrm{d} \varepsilon_{s(M I / M D)}^{M p} \\
-\mathrm{d} S_{r}^{M}=-\mathrm{d} S_{r}^{M e}-\mathrm{d} S_{r(S / / S D)}^{M p}-\mathrm{d} S_{r(L C)}^{M p}-\mathrm{d} S_{r(M I / M D)}^{M p}
\end{array}\right.
$$

where $\mathrm{d} \varepsilon_{v}^{M e}, \mathrm{~d} \varepsilon_{v(L C)}^{M p}$ and $\mathrm{d} \varepsilon_{v(M I / M D)}^{M p}$ are the elastic macrostructural volumetric strain increment, plastic macrostructural volumetric strain increments due to the stress point approaching the LC and the MI/ MD bounding surfaces, respectively; $\mathrm{d} \varepsilon_{s}^{M e}, \mathrm{~d} \varepsilon_{s(L C)}^{M p}$ and $\mathrm{d} \varepsilon_{s(M I / M D)}^{M p}$ are the elastic macrostructural shear strain increment, plastic macrostructural shear strain increments due to the stress point approaching the LC and the MI/ MD bounding surfaces, respectively; $\mathrm{d} S_{r}^{M e}, d S_{r(S I / S D)}^{M p}, d S_{r(L C)}^{M p}$ and $d S_{r(M I / M D)}^{M p}$ are the elastic increment of the macrostructural degree of saturation and the plastic increments of the macrostructural degree of saturation due to the stress point approaching SI/SD, LC and MI/MB bounding surfaces, respectively.

\section{Elastic behavior}

The elastic strain increments are given by:

$$
\left\{\begin{array}{l}
\mathrm{d} \varepsilon_{v}^{M e}=\frac{\kappa}{v} \frac{\mathrm{d} p^{*}}{p^{*}} \\
\mathrm{~d} \varepsilon_{s}^{M e}=\frac{2 \kappa(1+v)}{9 v p^{*}(1-2 v)} d q \\
-\mathrm{d} S_{r}^{M e}=\frac{\kappa_{w}}{s^{*}+p_{r e f}^{w}} \mathrm{~d} s^{*} \\
\mathrm{~d} \varepsilon_{v}^{m}=\frac{\kappa_{m}}{v} \frac{\mathrm{d} \hat{p}}{\hat{p}+p_{r e f}^{m}}
\end{array}\right.
$$

where $\kappa$ is the slope of the elastic swelling line in the $\left(v: \ln p^{*}\right)$ plane; $v$ is the total 
specific volume; $v$ is the Poisson's ratio; $\kappa_{w}$ is an additional elastic constant; $\kappa_{m}$ is the microscopic elastic constant; $p_{\text {ref }}^{w}$ and $p_{r e f}^{m}$ are reference stresses.

Plastic behavior related to LC bounding surface

The first part of the plastic volumetric strain increment caused by the stress point approaching the LC bounding surface is written as:

$$
\mathrm{d} \varepsilon_{v(L C)}^{M p}=R_{L C} \Lambda_{L C} \frac{\partial f_{L C}}{\partial p^{*}}
$$

where $\Lambda_{L C}$ is the non-negative loading index of the LC bounding surface; $R_{L C}$ is a scaling function controlling the hardening rate of the LC loading surface. The corresponding plastic shear strain increment is then defined as:

$$
\mathrm{d} \varepsilon_{s(L C)}^{M p}=R_{L C} \Lambda_{L C} \frac{\partial f_{L C}}{\partial q}
$$

The plastic change of the degree of saturation caused by the stress point approaching the LC bounding surface is given by:

$$
\mathrm{d} S_{r(L C)}^{M p}=k_{w s} R_{L C} \Lambda_{L C} \frac{\partial f_{L C}}{\partial p^{*}}
$$

where $k_{w s}$ is the coupling parameter controlling the magnitude of the change of the degree of saturation due to the macrostructural deformation.

According to Yao et al. (2012) for overconsolidated soil, the scaling function $R_{L C}$ can be defined as:

$$
R_{L C}=R^{\gamma_{L C}\left(M_{f}-\eta^{*}\right)} \frac{M^{\gamma_{L C}}-\eta^{* \gamma_{L C}}}{M_{f}^{\gamma_{L C}}-\eta^{* \gamma_{L C}}}
$$


where $R$ represents the size ratio between the current LC stress surface and the LC bounding surface with $R=p_{m}^{*}(0) / \bar{p}_{m}^{*}(0) ; \gamma_{L C}$ is a soil parameter; $M_{f}$ is the potential failure stress ratio which is equal to the ratio between the current mean unsaturated effective stress $p^{*}$ and the corresponding deviator stress on the Hvorslev envelope $q_{f}$, as show in Figure 5, expressed as:

$$
M_{f}=\frac{q_{f}}{p^{*}}=6\left[\sqrt{\frac{k}{R}\left(1+\frac{k}{R}\right)}-\frac{k}{R}\right]
$$

where $k=M^{2} /[12(3-M)]$.

A hardening law has been defined to describe the evolution of the bounding surface. The size change of the LC bounding surface is assumed to be related to the plastic volumetric strains, $d \varepsilon_{v(L C)}^{M p}$ and $d \varepsilon_{v(M I / M D)}^{M p}$ :

$$
d \bar{p}_{m}^{*}(0)=\bar{p}_{m}^{*}(0) \frac{v}{\lambda(0)-\kappa}\left(d \varepsilon_{v(L C)}^{M p}+d \varepsilon_{v(M I / M D)}^{M p}\right)
$$

A second hardening law is then introduced, describing the change of inclination of the LC bounding surface due to plastic strains, representing the change of anisotropy with plastic strains. Wheeler et al. (2003) suggested a rotational hardening law, assuming that the plastic volumetric strain attempts to drag the value of $\alpha$ towards an instantaneous target value $\chi_{v}$ that is dependent on the current value of the stress ratio. Simultaneously, the plastic shear strain is assumed to drag $\alpha$ towards a different target value $\chi_{d}$. This rotational hardening law has been adopted in this model, defined by:

$$
d \alpha=\omega\left[\left(\chi_{v}-\alpha\right)\left\langle d \varepsilon_{v(L C)}^{M p}+d \varepsilon_{v(M I / M D)}^{M p}\right\rangle+\omega_{d}\left(\chi_{d}-\alpha\right)\left|d \varepsilon_{s}^{M p}\right|\right]
$$

where $\omega$ is a soil parameter which controls the relative effectiveness of the plastic shear 
strain and plastic volumetric strain in determining the overall current target value for $\alpha ; \omega_{d}$ is another soil parameter which controls the rate at which $\alpha$ approaches its current target value.

According to Wheeler et al. (2003): $\chi_{v}\left(\eta^{*}\right)=3 / 4 \eta^{*}$, and according to Wheeler (1997), Kobayashi et al. (2003) and Yin et al. (2015): $\chi_{d}\left(\eta^{*}\right)=0$. Then, considering the full saturation as a special case, the parameters $\omega$ and $\omega_{d}$ can be determined by the methods proposed by Wheeler et al. (2003), Leoni et al. (2008) and Yin et al. (2011), as follows:

$$
\left\{\begin{array}{l}
\omega_{d}=\frac{3\left(4 M^{2}-4 \eta_{K 0}^{2}-3 \eta_{K 0}\right)}{8\left(\eta_{K 0}^{2}-M^{2}+3 \eta_{K 0}\right)} \\
\omega=\frac{1+e_{0}}{\lambda(s)-\kappa} \ln \frac{10-2 \alpha_{K 0} \beta}{M^{2}-2 \alpha_{K 0} \beta}
\end{array}\right.
$$

where $\eta_{K 0}=\left(1+2 K_{0}\right) /\left[3\left(1-K_{0}\right)\right]$ is the stress ratio at $K_{0}$-consolidated state with the assumption that $p_{s}^{*}=0$.

The initial inclination of the LC bounding surface is expressed as (Wheeler 2003; Yin et al. 2011):

$$
\alpha_{K 0}=\frac{\eta_{K 0}^{2}+3 \eta_{K 0}-M^{2}}{3}
$$

\section{Plastic behavior related to MI and MD bounding surfaces}

The plastic volumetric strain increment caused by the stress point approaching the MI or MD bounding surface is given by:

$$
\left\{\begin{array}{lll}
\mathrm{d} \varepsilon_{v(M I)}^{M_{p}}=R_{M I / M D} \Lambda_{M I} \frac{\partial g_{M I}}{\partial \hat{p}} d_{I} & \text { for } & d \hat{p}<0 \\
\mathrm{~d} \varepsilon_{v(M D)}^{M_{p}}=R_{M I / M D} \Lambda_{M D} \frac{\partial g_{M D}}{\partial \hat{p}} d_{D} & \text { for } & d \hat{p}>0
\end{array}\right.
$$


where $\Lambda_{M I}$ and $\Lambda_{M D}$ are the non-negative loading indexes of the MI and MD bounding surfaces, respectively; $R_{M I / M D}$ is the scaling function for the MI/MD bounding surface; $d_{I}$ and $d_{D}$ are soil parameters which control the value of $\mathrm{d} \varepsilon_{v(M I / M D)}^{M p} ; g_{M I}$. and $g_{M D}$ are plastic potential functions. Alonso et al. (1999) proposed that the soils parameters $d_{I}$ and $d_{D}$ are related to overconsolidation ratio. When the value of $d_{D}$ is negative, the aggregates swell into the macropores and do not contribute significantly to the global deformation. The test results by Monroy et al. (2010) for compacted London clays showed that the decrease of macroporosity is small during wetting except for wetting from suction $40 \mathrm{kPa}$ to $0 \mathrm{kPa}$. Furthermore, the test results by Alonso et al. (1995) for loosely compacted clays showed the decrease of global volume during wetting from suction $700 \mathrm{kPa}$ to $10 \mathrm{kPa}$. To simplify the expression of soils parameters $d_{I}$ and $d_{D}$, the above behaviors during wetting are attributed to the collapse of macropores.

A non-associated flow rule has been adopted for the MI/MD bounding surface and the derivation of $g_{M I}$ and $g_{M D}$ gives:

(31) $\frac{\partial g_{M I / M D}}{\partial p^{\prime}}=0, \quad \frac{\partial g_{M I}}{\partial s}=+1, \quad \frac{\partial g_{M D}}{\partial s}=-1$

Furthermore, the corresponding plastic shear strain increment was assumed to be zero when the stress point approaches the MI or MD bounding surface.

The plastic change of the degree of saturation caused by the stress point approaching the MI or MD bounding surface is given by:

$$
\mathrm{d} S_{r(M I / M D)}^{M p}=k_{w s} \mathrm{~d} \varepsilon_{v(M I / M D)}^{M p}
$$


The scaling function $R_{M I / M D}$ is defined by:

$$
R_{M I / M D}= \begin{cases}\left(\hat{p} / \hat{p}_{I}\right)^{\gamma_{M I D}} & \text { for } d \hat{p}>0 \\ \left(\hat{p}_{D} / \hat{p}\right)^{\gamma_{M I D}} & \text { for } d \hat{p}<0\end{cases}
$$

where $\gamma_{M I D}$ is a soil parameter.

For the MI and MD bounding surfaces, the hardening parameters are $\hat{p}_{I}$ and $\hat{p}_{D}$, respectively. The change of position of the MI and MD bounding surfaces is given by:

$$
\left\{\begin{array}{l}
\frac{\mathrm{d} \hat{p}_{I}}{\hat{p}_{I}+p_{r e f}^{m}}=\frac{v}{\kappa_{m}}\left(\Lambda_{M I} \frac{\partial g_{M I}}{\partial \hat{p}}+k_{M I D} \Lambda_{M D} \frac{\partial g_{M D}}{\partial \hat{p}}\right) \text { for } d \hat{p}<0 \\
\frac{\mathrm{d} \hat{p}_{D}}{\hat{p}_{D}+p_{r e f}^{m}}=\frac{v}{\kappa_{m}}\left(\Lambda_{M D} \frac{\partial g_{M D}}{\partial \hat{p}}+k_{M I D} \Lambda_{M I} \frac{\partial g_{M I}}{\partial \hat{p}}\right) \text { for } \quad d \hat{p}>0
\end{array}\right.
$$

where the parameter $k_{M I D}$ controls the shifting of the MI (or MD) bounding surface due to the current stress point approaching the MD (or MI) bounding surface. In general, the range of values for the parameter $k_{M I D}$ is 0 to 1 . When $k_{M I D}=0$, the hardening law becomes isotropic; when $k_{M I D}=1$, the hardening law becomes purely kinematic.

\section{Plastic behavior related to SI and SD bounding surfaces}

The plastic change of the degree of saturation due to the stress point approaching the SI or SD bounding surface is given by:

$$
\mathrm{d} S_{r(S I / S D)}^{M p}=R_{S I / S D} \Lambda_{S I / S D} \frac{\partial f_{S I / S D}}{\partial s^{*}}
$$

where $\Lambda_{S I / S D}$ is the loading index of the SI and SD bounding surfaces; $R_{S I / S D}$ is the scaling function for the MI/MD bounding surface defined by:

$$
R_{S I / S D}= \begin{cases}\left(s^{*} / s_{I}^{*}\right)^{\gamma_{S D D}} & \text { for } d s^{*}>0 \\ \left(s_{I}^{*} / s^{*}\right)^{\gamma_{S I D}} & \text { for } d s^{*}<0\end{cases}
$$


where $\gamma_{S I D}$ is a soil parameter. For the SI and SD bounding surfaces, the hardening parameters are $s_{I}^{*}$ and $s_{D}^{*}$, respectively.

The change of position of the SI and SD bounding surfaces is given by:

$$
\frac{\mathrm{d} s_{I}^{*}}{s_{I}^{*}+p_{r e f}^{w}}=\frac{\mathrm{d} s_{D}^{*}}{s_{D}^{*}+p_{r e f}^{w}}=\frac{1}{\lambda_{w}-\kappa_{w}}\left(-\mathrm{d} S_{r(S I / S D)}^{M p}+d S_{r(L C)}^{M p}+d S_{r(M I / M D)}^{M p}\right)
$$

where $\lambda_{w}$ is the plastic constant for the liquid phase. To simplify the part of the model corresponding to the water retention behavior, the main drying and wetting lines are assumed to be linear in a semi-logarithmic plot. It is, however, possible to replace them by nonlinear forms (e.g., Brooks and Corey, 1964; Van Genuchten, 1980).

\section{Model parameters}

The parameters used in the suggested model can be classified into the following categories: normal consolidation line, critical state line, elastic constants, plastic constants, plastic potential functions, and hardening laws. The tests required for determining these parameters include isotropic consolidation compression tests at different suctions, triaxial compression tests at different effective confining stresses for saturated soils, suction-controlled oedometer tests under constant volume and suction-controlled cyclic tests at low and high net mean stresses. The parameters can be determined as follows:

(1) The slope $\lambda(s)$ and the intercept $N(s)$ of the normal compression lines are obtained from isotropic compression tests at different suctions. The expression of the parameter $\lambda(s)$ proposed by Alonso et al. (1990) is used, as follow:

$$
\lambda(s)=\lambda(0)\left[\left(1-r_{\lambda}\right) \exp \left(-\beta_{\lambda} s\right)+r_{\lambda}\right]
$$


The expression of the parameter $N(s)$ is assumed to be similar to the expression of $\lambda(s)$ and it is expressed as:

$$
N(s)=N(0)\left[\left(1-r_{N}\right) \exp \left(-\beta_{N} s\right)+r_{N}\right]
$$

where $r_{\lambda}, \beta_{\lambda}, r_{N}$ and $\beta_{N}$ are soil parameters determined by curve fitting from the normal compression lines at different suctions.

(2) The slope $M$ and the intercept $\mu$ of the critical state line in the $\left(q: p^{*}\right)$ plane are obtained from shear tests. For simplicity, $M$ and $\mu$ are assumed to be constant, independent of the suction. This implies that the critical state line is unique for different suctions, from zero to several hundred $\mathrm{kPa}$ in the $\left(p^{*}: q\right)$ plane, as shown by Sivakumar (1993), Wheeler and Sivakumar (2000) on compacted Speswhite kaolin and by Barrera (2002) on compacted Barcelona clayey silt. Then, the stress results at or nearby the critical state of at least three triaxial compression tests at different net confining stresses and saturated state are plotted in the $\left(q: p^{*}\right)$ plane to obtain the slope $M$ and the intercept $\mu$ of the critical state line.

(3) The elastic constant $\kappa$ can be determined from the unloading and reloading parts of the normal consolidation line in the $\left(v: \ln p^{*}\right)$ plane obtained by an isotropic compression test on saturated soil specimen. The water elastic constant $\kappa_{w}$ is the slope of the scanning line in the $\left(S_{r}^{M}: \ln \left(s^{*}+p_{r e f}^{w}\right)\right)$ plane. The microstructural elastic constant $\kappa_{m}$ and the parameter $p_{r e f}^{m}$ can be determined by mercury intrusion porosimetry tests during wetting and drying paths. Furthermore, $\kappa_{m}$ can also be determined from wetting and drying tests for highly over-consolidated soils that have negligible macropores (Cui et al. 2002). 
(4) The water plastic constant $\lambda_{w}$ is the slope of the main wetting and drying lines in the $\left(S_{r}^{M}: \ln \left(s^{*}+p_{r e f}^{w}\right)\right)$ plane under constant volume condition. It should be determined by a suction-controlled oedometer test under constant volume condition. Besides, the coupling parameter $k_{w s}$ controls the effect of the plastic macro-volumetric strain on the degree of saturation. Therefore, it can be calibrated by an isotropic consolidation compression test at a given suction. When the suction-controlled oedometer test under constant volume is not possible, $\lambda_{w}$ and $k_{w s}$ can be calibrated simultaneously by at least two suction-controlled tests at different constant confining stresses.

(5) When the stress point is far away from the LC bounding surface, the part of plastic macrostructural volumetric strain increments due to the stress point approaching the LC bounding surfaces, i.e., $\mathrm{d} \varepsilon_{v(L C)}^{p}$ can be ignored. Therefore, the plastic potential parameters, $d_{I}$ and $d_{D}$, can be calibrated by a suction-controlled cyclic test at low net mean stress.

(6) There are six hardening parameters, i.e., $\bar{p}_{m}^{*}(0), \hat{p}_{I}, \hat{p}_{D}, s_{I}^{*}, s_{D}^{*}, k_{M I D}$ and three scaling parameters, i.e., $\gamma_{L C}, \gamma_{S I D}, \gamma_{M I D}$ in this model. The initial value of $\bar{p}_{m}^{*}(0)$ can be determined by an isotropic compression test at $s=0$; the initial values of $\hat{p}_{I}, \hat{p}_{D}$, $s_{I}^{*}$ and $s_{D}^{*}$ can be determined by suction-controlled tests. Besides, the hardening parameter $k_{M I D}$ and the scaling parameters $\gamma_{L C}, \gamma_{S I D}$ and $\gamma_{M I D}$ can be determined simultaneously by these testes, which values also affect the initial values of these hardening parameters.

\section{Experimental validation}




\section{Brief introduction of the tests used in the simulation}

Two series of tests on expansive clays were selected for simulations. The first series consists of multiple wetting-drying cycles on Boom clay by Alonso et al. (1995). The second series consists of triaxial tests on ZY expansive clay by Zhan and Ng (2006), Chen (2007) and Chen and $\mathrm{Ng}(2013)$.

\section{Multiple wetting-drying cycle tests on Boom clay}

Boom clay has a liquid limit of $55.9 \%$, a plasticity index of $29.2 \%$. Kaolinite, illite and montmorillonite contents are $20 \%, 30 \%$ and $10 \%$, respectively. Oedometer tests were carried out on samples with an initial dry density of $14 \mathrm{kN} / \mathrm{m}^{3}$. The soil specimens were first loaded at constant water content, and then an initial suction of 500 or $700 \mathrm{kPa}$ was applied. After equilibrium at this initial suction, multiple wetting-drying cycles were applied with suction varying from 500 or $700 \mathrm{kPa}$ to $10 \mathrm{kPa}$. Tests with wetting-drying cycles under constant net mean stresses of 20, 100 and $400 \mathrm{kPa}$ were simulated.

\section{Triaxial tests on ZY expansive clay}

The ZY expansive clay has a liquid limit of $50 \%$, a plastic index of $31 \%$, a specific gravity $\left(G_{s}\right)$ of 2.67 , and a clay content of $39 \%$. Based on the USCS classification, the soil is a medium-high plastic clay. The value of the one-dimensional free swelling deformation is approximately $16 \%$ for the compacted specimen. The soil can be classified as a medium expansive soil in agreement with the criterion proposed by Sridharan and Prakash (2000). The selected tests with their experimental procedures are summarized below:

(1) Three wetting and drying cycle tests under different constant net mean stresses (i.e., 40, 
70 and $100 \mathrm{kPa}$ ) were selected for the simulations. The first specimen was consolidated up to a net mean stress of $40 \mathrm{kPa}$, and then subjected to a wetting and drying cycle. The suction was changed from $540 \mathrm{kPa}$ to $10 \mathrm{kPa}$ and then to $400 \mathrm{kPa}$. The other two specimens were firstly wetted to a suction of $200 \mathrm{kPa}$ from the initial state, followed by a consolidation stage under different net mean stresses (70 and $100 \mathrm{kPa}$ ), and then subjected to a wetting and drying cycle during which the suction decreased from $200 \mathrm{kPa}$ to $10 \mathrm{kPa}$ and then increased to $350 \mathrm{kPa}$.

(2) Fourteen fully drained shearing tests under different constant net confining stresses and suctions were selected for the simulations. Firstly, the specimens were wetted to different suctions $(200,100,50$ and $25 \mathrm{kPa})$ under a net mean stress of $20 \mathrm{kPa}$. Then, they were consolidated under net mean stresses of 50,200 and $350 \mathrm{kPa}$ at different suctions. Unlike other tests, two soil specimens wetted to zero suction were consolidated under 50 and $350 \mathrm{kPa}$. Finally, all soil specimens were sheared under drained condition at constant net confining stress and constant suction.

(3) Six suction-controlled drained triaxial tests at different constant net mean stresses were selected for the simulations. These soil specimens were wetted at different suctions (200, 100 and $0 \mathrm{kPa}$ ) under a net mean stress of $20 \mathrm{kPa}$. Then, three of them were sheared to a deviator stress of $11 \mathrm{kPa}$; the other three were sheared to a deviator stress of $20 \mathrm{kPa}$ under a constant net mean stress of $20 \mathrm{kPa}$. Afterwards, these specimens were compressed to a net mean stress of $350 \mathrm{kPa}$ under different constant net stress ratios $(\eta=0.55,1.0)$. Finally, they were sheared under drained condition at a constant net mean stress of $350 \mathrm{kPa}$. 


\section{Test simulations}

Multiple wetting-drying cycle tests on Boom clay

According to section 2.4, all the parameters used in the subsequent simulations have been determined based on isotropic consolidation compression tests at different suction levels and on suction-controlled cyclic tests. In order to determine the model parameters of microstructure and SWRC, the results on Boom clay obtained by Romero et al. (1999) were used. The values of model parameter are summarized in Table 1. The values of the initial state parameters are given in Table 2.

Figure 6 shows the variations of the specific volume during wetting and drying cycles. A comparison between measured and calculated results shows that the suggested model can quantitatively describe the behavior of Boom clay under multiple wetting and drying cycles. An accumulated plastic contraction grows with the increase of the net confining stress. Furthermore, an equilibrium state of deformation is almost reached after the applied wetting-drying cycles. The predicted deformations at 20 and $400 \mathrm{kPa}$ net confining stresses during the wetting and drying cycles are close to the test results; however, the predicted deformation at $100 \mathrm{kPa}$ net confining stress is smaller than the experimental one when a unique group of parameters for different net confining stresses is used. Note that the coupling parameters $d_{I}$ and $d_{D}$ were assumed constant and independent of the degree of saturation and of the overconsolidation ratio in the model. Nonetheless, the nonlinear behavior upon wetting and drying cycles could be reproduced, thanks to the bounding surface concept applied to LC and MI/MD yield surfaces. 
Triaxial tests on ZY expansive clay

According to section 2.4, all the parameters used in the subsequent simulations have been determined based on isotropic consolidation compression tests at different suction levels, on triaxial compression tests at different effective confining stresses for saturated soils and on suction-controlled cyclic tests. The values of model parameter are summarized in Table 3 . The values of the initial state parameters are given in Table 4. Since the mercury intrusion porosimetry test results are not available, the initial micro porosity and the elastic constants for the microstructure used in the simulation cannot be directly obtained. Gens et al. (2011) suggested that the initial ratio of micro voids to macro voids is linked to the initial dry density for a given compacted clay. To determine the initial ratio for ZY expansive clay, the mercury intrusion porosimetry test results on a similar type of clay by Romero et al. (1999) and Nowamooz and Masrouri (2010) have been adopted. By means of simple interpolation, the initial ratio of micro porosity to total porosity for ZY expansive clay with initial dry densities of $1.56 \mathrm{Mg} / \mathrm{m}^{3}$ has been estimated equal to 0.4 . Besides, according to the results of one-dimensional free swelling, a value of $\kappa_{m}=0.008$ has been chosen.

(1) Wetting and drying cycle under constant net mean stress

Figure 7 shows the variations of the specific volume and the degree of saturation for wetting and drying cycle tests. The comparison between measured and calculated results shows that the model can describe reasonably well the behavior of $Z Y$ expansive clay upon the wetting and drying cycle. Both the swelling deformation along a wetting path and the accumulated plastic swelling deformation after a wetting-drying cycle increase with the 
decrease of the net confining stress. Furthermore, the hydraulic hysteresis is well reproduced by the model. The degree of saturation on the drying path is larger than the one on the wetting path at a given suction. In addition to the hydraulic hysteresis, the SWRC of a given soil also depends on the net confining stress and on the specific volume. The degree of saturation increases with the net confining stress. Besides, the bounding surface approach can reproduce the smooth transition between the scanning line and the bounding surfaces of SWRC.

(2) Drained shearing tests under different constant net confining stresses

Figures 8 to 10 show the variations of the deviator stress, the specific volume and the degree of saturation during the triaxial tests. The comparison between the measured and calculated results shows that the model can quantitatively describe the shearing behavior of unsaturated expansive soil. The deviator stresses reach an almost steady state, i.e., the critical state, in the last phase of shearing, and the shear strength increases with the suction and the net confining stress. The predicted changes of the deviator stress with the matric suction is close the experimental results under net confining stresses of 200 and $350 \mathrm{kPa}$; however, the predicted changes of the deviator stress with the matric suction is smaller than the experimental one under a net confining stress of $50 \mathrm{kPa}$. This discrepancy at the latter condition is attributed to the assumption of a unique critical state line in the $\left(p^{*}: q\right)$ plane. Besides, the final value of the specific volume decreases with the suction increase under a net confining stress of $50 \mathrm{kPa}$. On the other hand, the final value of the specific volume grows with the increase of suction under net confining stresses of 200 and $350 \mathrm{kPa}$. Finally, the degree of saturation of each specimen increases with the axial strain. 
Furthermore, to highlight the influence of the anisotropy, test simulations using the isotropic model (setting $\alpha_{K 0}=\omega=0$ ) were compared with the measured results in Figure 11 . It can be seen that the calculated deviator stress for each specimen is larger when considering the anisotropy and more in agreement with the experimental data, especially at low net confining stresses. Moreover, the calculated specific volume of each specimen is larger when considering the anisotropy and, as a consequence, the predicted degree of saturation is also larger. The calculated specific volume considering anisotropy is closer to the experimental data at low matric suction. However, an opposite result is obtained at high matric suction. The evolution of the anisotropy with the matrix suction will have to be better analyzed in further studies.

(3) Drained shearing tests under constant net mean stress

Figures 12 and 13 show the variations of the deviator stress, the specific volume and the degree of saturation during anisotropic compressions at constant net stress ratios of 0.55 and 1.0, followed by shearing at constant net mean stress. A comparison between the measured and calculated results shows that the model can reproduce with reasonable accuracy the soil behavior during anisotropic compression and shearing. The deviator stress at high strain levels increases with the suction and the effect of the net stress ratio is not significant. As shown in Figure 13(a), the predicted deviator stress of $0 \mathrm{kPa}$ matric suction is larger than the experimental data due to the fact that the specimen broke into pieces during shearing. Besides, the value of the specific volume increases with the suction. This phenomenon is consistent with the volume change during the drained shearing tests under constant net confining stresses of 200 and $350 \mathrm{kPa}$. Furthermore, the test simulations with the isotropic model 
compared to the test results in Figures 14 demonstrate the improvement of the simulation by considering the anisotropy of the yield surface.

\section{Conclusions}

In this paper, the work input expression was deduced to unsaturated expansive clays considering double porosity, based on the porous media theory. Unlike the conventional assumptions used to derivate a work input expression for general unsaturated soils, the adsorbed water phase assumptions used to derivate a work input expression for general unsaturated soils from the capillary water phase, and the micropores were assumed to separate from the macropores. An inter-aggregate stress was then derived, which is the work-conjugate of the macrostructural strain increment, to account for both the physico-chemical and the capillary effects due to the coupling between the pore water and the other phases at the macroscopic level. Based on the input work expression, four groups of work-conjugate variables were selected to establish a constitutive model, which were $\left(p^{*}, \varepsilon_{v}^{M}\right),\left(q, \varepsilon_{s}^{M}\right)$, $\left(s^{*}, S_{r}^{M}\right)$ and $\left(\hat{p}, \varepsilon_{v}^{m}\right)$. The former three were used for describing the macrostructural behavior, and the last one was used for describing the microstructural deformation. The proposed average skeleton stress $p^{*}$ is a function of the net stress, the macrostructure degree of saturation representing the capillary water content, and the suction. The expression of the microstructure effective stress $\hat{p}$ implies that the changes in the external applied stresses and suction affect the aggregate sizes.

A new hydro-mechanical model was then proposed which considers the interaction between the micro and macro soil structures. The bounding surface concept was adopted for 
modeling both the stress-strain relation and the water retention curve, which leads to a simplified expression for the plastic potential parameters $d_{I}$ and $d_{D}$. An anisotropic expression of the loading-collapse yield surface was also introduced in order to improve the model predictive ability under triaxial condition. Wetting and drying cycle tests and triaxial compression tests on expansive clay were selected for the simulation. The comparisons between numerical and experimental results demonstrate the ability of the model to reproduce the coupled hydro-mechanical behavior of unsaturated expansive clays.

\section{Acknowledgments}

This research was financially supported by the National Natural Science Foundation of China (Grant No. 41372285, 51579179, 51239010), the China Postdoctoral Science Foundation (Grant No. 2015M582314), and the Erasmus Mundus Programme TANDEM. These supports are greatly appreciated.

\section{References}

Alonso, E.E., Gens, A., and Josa, A. 1990. A constitutive model for partially saturated soils. Géotechnique, 40(3), 405-430. doi: 10.1680/geot.1990.40.3.405.

Alonso, E.E., Lloret, A., Gens, A., and Yang, D.Q. 1995. Experimental behaviour of highly expansive double-structure clay. In 1st International Conference on Unsaturated Soils, Paris, 6-8 September 1995. Edited by E.E. Alonso and P. Delage. Balkema, Rotterdam, 
the Netherlands. Vol. 1, pp. 11-16.

Alonso, E.E., Pereira, J.-M., Vaunat, J., and Olivella, S. 2010. A microstructurally based effective stress for unsaturated soils. Géotechnique, 60(12), 913-925. doi: 10.1680/geot.8.P.002.

Al-Sharrad, M. A., and Gallipoli, D. 2014. An elasto-plastic model for unsaturated soils with evolving anisotropy. In Proceedings of the 6th International Conference on Unsaturated Soils, UNSAT 2014, Sudney, Australia. Edited by N. Khalili, A.R. Russell and A. Khoshghalb. pp. 433-439. doi: 10.1201/b17034-60.

Baker, R., and Frydman, S. 2009. Unsaturated soil mechanics: Critical review of physical foundations. Engineering Geology, 106(1-2), 26-39. doi:10.1016/j.enggeo.2009.02.010.

Banerjee, P.K., and Yousif, N.B. 1986. A plasticity model for the mechanical behaviour of anisotropically consolidated clay. International Journal for Numerical and Analytical Methods in Geomechanics, 10(5), 521-541. doi: 10.1002/nag.1610100505.

Barenblatt, G.I., Zheltov, Iu.P., and Kochina, I.N. 1960. Basic concepts in the theory of seepage of homogeneous liquids in fissured rocks. Journal of Applied Mathematics and Mechanics, 24(5), 1286-1303. doi: 10.1016/0021-8928(60)90107-6.

Barrera, M.B. 2002. Estudio experimental del comportamiento hidro-mecánico de suelos colapsables (in Spanish). Ph.D. thesis, Universitat Politecnica de Catalunya, Barcelona, Spain.

Borja, R.I., and Koliji, A. 2009. On the effective stress in unsaturated porous continua with 
double porosity. Journal of the Mechanics and Physics of Solids, 57(8), 1182-1193. doi: 10.1016/j.jmps.2009.04.014.

Brooks, R.H., and Corey, A.T. 1964. Hydraulic properties of porous media. Hydrology Paper No.3, Colorado State University, Fort Collins, Colorado.

Chen R. 2007. Experimental study and constitutive modelling of stress-dependent coupled hydraulic hysteresis and mechanical behaviour of an unsaturated soil. Ph.D. thesis, Hong Kong University of Science and Technology, Hong Kong.

Chen, R., and Ng, C.W.W. 2013. Impact of wetting-drying cycles on hydro-mechanical behavior of an unsaturated compacted clay. Applied Clay Science, 86, 38-46. doi: 10.1016/j.clay.2013.09.018.

Cui, Y.J., and Delage, P. 1996. Yielding and plastic behaviour of an unsaturated compacted silt. Géotechnique, 46(2), 291-311. doi: 10.1680/geot.1996.46.2.291.

Cui, Y.J., Yahia-Aissa, M., and Delage, P. 2002. A model for the volume change behaviour of heavily compacted swelling clays. Engineering Geology, 64(2-3), 233-250. doi: 10.1016/S0013-7952(01)00113-2.

Dafalias, Y.F., and Herrmann, L.R. 1982. Bounding surface formulation of soil plasticity. In Proceedings of the International Symposium on Soils under Cyclic and Transient Loading. Edited by G.N. Pande and O.C. Zienkiewicz. Wiley, New York. pp. 253-282.

Delage, P., and Lefebvre, G. 1984. Study of the structure of a sensitive Champlain clay and of its evolution during consolidation. Canadian Geotechnical Journal, 21(1), 21-35. doi: 
$10.1139 / \mathrm{t} 84-003$.

Delage, P., Tessier, D., and Marcel-Audiguier, M. 1982. Use of the Cryoscan apparatus for observation of freeze-fractured planes of a sensitive Quebec clay in scanning electron microscopy. Canadian Geotechnical Journal, 19(1), 111-114. doi: 10.1139/t82-011.

Della Vecchia, G., and Romero, E. 2013. A fully coupled elastic-plastic hydromechanical model for compacted soils accounting for clay activity. International Journal for Numerical and Analytical Methods in Geomechanics, 37(5), 503-535. doi: 10.1002/nag. 1116 .

Derjaguin, B.V., Churaev, N.V., and Muller, V.M. 1987. Surface Forces. Plenum Press, New York.

D’Onza, F., Gallipoli, D., and Wheeler, S.J. 2011. Effect of anisotropy on the prediction of unsaturated soil response under triaxial and oedometric conditions. In Proceedings of the 5th International Conference on Unsaturated Soils, Barcelona, Spain. Edited by E. Alonso and A. Gens. pp. 787-794. doi: 10.1201/b10526-122.

Gens, A., and Alonso, E.E. 1992. A framework for the behaviour of unsaturated expansive clays. Canadian Geotechnical Journal, 29(6), 1013-1032. doi: 10.1139/t92-120.

Gens, A., Alonso, E.E., Suriol, J., and Lloret, A. 1995. Effect of structure on the volumetric behaviour of a compacted soil. In 1st International Conference on Unsaturated Soils. Edited by E.E. Alonso and P. Delage. Paris, Balkema. Vol. 1, pp. 83-88.

Gens, A., Valleján, B., Sánchez, M., Imbert, C., Villar, M.V., and Van Geet, M. 2011. 
Hydromechanical behaviour of a heterogeneous compacted soil: experimental observations and modelling. Géotechnique, 61(5), 367-386. doi: 10.1680/geot.SIP11.P.015.

Hoffmann, C., Alonso, E.E., and Romero, E. 2007. Hydro-mechanical behaviour of bentonite pellet mixtures. Physics and Chemistry of the Earth, 32(8-14), 832-849. doi: 10.1016/j.pce.2006.04.037.

Houlsby, G.T. 1997. The work input to an unsaturated granular material. Géotechnique, 47(1), 193-196. doi: 10.1680/geot.1997.47.1.193.

Khalili, N., Witt, R., Laloui, L., Vulliet, L., and Koliji, A. 2005. Effective stress in double porous media with two immiscible fluids. Geophysical Research Letters, 32(15), L15309.1-L15309.5. doi: 10.1029/2005GL023766.

Kobayashi, I., Soga, K., Iizuka, A., and Ohta, H. 2003. Numerical interpretation of a shape of yield surface obtained from stress probe tests. Soils and Foundations, 43(3), 95-103. doi: 10.3208/sandf.43.3_95.

Leoni, M., Karstunen, M., and Vermeer, P.A. 2008. Anisotropic creep model for soft soils. Géotechnique, 58(3), 215-226. doi: 10.1680/geot.2008.58.3.215.

Li, X.S. 2005. Modelling of hysteresis response for arbitrary wetting/drying paths. Computers and Geotechnics, 32(2), 133-137. doi: 10.1016/j.compgeo.2004.12.002.

Liu, C., and Muraleetharan, K. 2006. Description of soil water characteristic curves using the bounding surface plasticity theory. In Proceedings of the 4th International Conference on 
Unsaturated Soils, Carefree, Arizona, April 2-6, 2006. Edited by G.A. Miller, C.E. Zapata, S.L. Houston and D.G. Fredlund. Vol. 2, pp. 2432-2440.

Lu, N., and Likos, W.J. 2006. Suction stress characteristic curve for unsaturated soils. Journal of Geotechnical and Geoenvironmental Engineerin, 132(2), 131-142. doi: 10.1061/(ASCE)1090-0241(2006)132:2(131).

Mašín, D. 2013. Double structure hydromechanical coupling formalism and a model for unsaturated expansive clays. Engineering Geology, 165(24), 73-88. doi: 10.1016/j.enggeo.2013.05.026.

Mašín, D., and Khalili, N. 2015. Swelling phenomena and effective stress in compacted expansive clays. Canadian Geotechnical Journal, 53(1), 134-147. doi: 10.1139/cgj-2014-0479.

Monroy, R., Zdravkovic, L., and Ridley, A. 2010. Evolution of microstructure in compacted London Clay during wetting and loading. Géotechnique, 60(2), 105-119. doi: 10.1680/geot.8.P.125.

Nowamooz, H., and Masrouri, F. 2010. Relationships between soil fabric and suction cycles in compacted swelling soils. Engineering Geology, 114(3-4), 444-455. doi: 10.1016/j.enggeo.2010.06.005.

Raveendiraraj, A. 2009. Coupling of mechanical behaviour and water retention behaviour in unsaturated soils. Ph.D. thesis, University of Glasgow, Scotland, UK.

Romero, E., Gens, A., and Lloret, A. 1999. Water permeability, water retention and 
microstructure of unsaturated compacted Boom clay. Engineering Geology, 54(1-2), 117-127. doi:10.1016/S0013-7952(99)00067-8.

Romero, E., Della Vecchia, G., and Jommi, C. 2011. An insight into the water retention properties of compacted clayey soils. Géotechnique, 61(4), 313-328. doi: 10.1680/geot.2011.61.4.313.

Sheng, D., Sloan, S.W., and Gens, A. 2004. A constitutive model for unsaturated soils: thermomechanical and computational aspects. Computational Mechanics, 33(6), 453-465. doi: 10.1007/s00466-003-0545-x.

Sivakumar, V. 1993. A critical state framework for unsaturated soil. Ph.D. thesis, University of Sheffield, UK.

Sridharan, A., and Prakash, K. 2000. Classification procedures for expansive soils. Proceedings of the Institution of Civil Engineers, Geotechnical Engineering, 143(4), 235-240. doi: 10.1680/geng.2000.143.4.235.

Sridharan, A., Altschaeffl, A.G., and Diamond, S. 1971. Pore size distribution studies. Journal of the Soil Mechanics and Foundations Division, 97(5), 771-787.

Stropeit, K., Wheeler, S.J., and Cui, Y.J. 2008. An anisotropic elasto-plastic model for unsaturated soils. In Proceedings of 1st European Conference on Unsaturated Soils, E-UNSAT 2008, Durham, United Kingdom, 2-4 July 2008. Edited by D.G. Toll, C.E. Augarde, D. Gallipoli and S.J. Wheeler. pp. 625-631. doi: 10.1201/9780203884430.ch84.

Sun, W., and Sun, D. 2012. Coupled modelling of hydro-mechanical behaviour of unsaturated 
compacted expansive soils. International Journal for Numerical and Analytical Methods in Geomechanics, 36(8), 1002-1022. doi: 10.1002/nag.1036.

Tian, H.H., and Wei, C.F. 2014. A NMR-based testing and analysis of adsorbed water content (in Chinese). Scientia Sinica Technologica, 44(3), 295-305. doi: 10.1360/092013-1133.

Tuller, M., Or, D., and Dudley, L.M. 1999. Adsorption and capillary condensation in porous media: liquid retention and interfacial configurations in angular pores. Water Resources Research, 35(7), 1949-1964. doi: 10.1029/1999WR900098.

Van Genuchten, M.Th. 1980. A closed-form equation for predicting the hydraulic conductivity of unsaturated soil. Soil Science Society of America Journa, 44(5), 892-898. doi: 10.2136/sssaj1980.03615995004400050002x.

Wheeler, S.J. 1997. A rotational hardening elasto-plastic model for clays. In Proceedings of the 14th International Conference on Soil Mechanics and Foundation Engineering. Hamburg, A.A. Balkema, Rotterdam. Vol. 1, pp. 431-434.

Wheeler, S.J., and Sivakumar, V. 1995. An elasto-plastic critical state framework for unsaturated soil. Géotechnique, 45(1), 35-53. doi: 10.1680/geot.1995.45.1.35.

Wheeler, S.J., and Sivakumar, V. 2000. Influence of compaction procedure on the mechanical behaviour of an unsaturated compacted clay. Part 2: Shearing and constitutive modelling. Géotechnique, 50(4), 369-376. doi: 10.1680/geot.2000.50.4.369.

Wheeler, S.J., Näätänen, A., Karstunen, M., and Lojander, M. 2003. An anisotropic elastoplastic model for soft clays. Canadian Geotechnical Journal. 40(2), 403-418. doi: 
$10.1139 / \mathrm{t} 02-119$.

Yao, Y., and Kong, Y. 2012. Extended UH Model: Three-Dimensional Unified Hardening Model for Anisotropic Clays. Journal of Engineering Mechanics, 138(7), 853-866. doi: 10.1061/(ASCE)EM.1943-7889.0000397.

Yin, Z.-Y., Karstunen, M., Chang, C.S., Koskinen, M., and Lojander, M. 2011. Modeling time-dependent behavior of soft sensitive clay. Journal of Geotechnical and Geoenvironmental Engineering, 137(11), 1103-1113. doi: 10.1061/(ASCE)GT.1943-5606.0000527.

Yin, Z.-Y., Yin, J.H., and Huang, H.W. 2015. Rate-dependent and long-term yield stress and strength of soft Wenzhou marine clay: experiments and modeling. Marine Georesources \& Geotechnology, 33(1), 79-91. doi:10.1080/1064119X.2013.797060.

Zhan, T.L., and Ng, C.W. 2006. Shear strength characteristics of an unsaturated expansive clay. Canadian Geotechnical Journal, 43(7), 751-763. doi: 10.1139/t06-036.

Zhao, C.G., Liu, Y., and Gao, F.P. 2010. Work and energy equations and the principle of generalized effective stress for unsaturated soils. International Journal for Numerical and Analytical Methods in Geomechanics, 34(9), 920-936. doi: 10.1002/nag.839.

Zhao, C.G., Liu, Z.Z., Shi, P.X., Li, J., Cai, G.C., and Wei, C.F. 2015. Average Soil Skeleton Stress for Unsaturated Soils and Discussion on Effective Stress. International Journal of Geomechanics, D4015006. doi: 10.1061/(ASCE)GM.1943-5622.0000610. 


\section{List of figure captions}

Figure 1 Yield curves based on experimental data at various suctions by (a) Cui and Delage (1996); (b) Zhan and Ng (2006) and Chen (2007)

Figure 2 Illustration of anisotropic loading collapse bounding surface

Figure 3 Illustration of MI and MD bounding surfaces

Figure 4 Illustration of SI and SD bounding surfaces

Figure 5 Illustration of the parabolic Hvorslev envelope

Figure 6 Comparisons between the measured and computed results of the multiple wetting and drying cycle tests for Boom Clay

Figure 7 Comparisons between the measured and computed results of the wetting and drying cycle test for ZY expansive clay

Figure 8 Comparisons between the measured and computed results of drained shear tests at different suctions under net confining stress of $350 \mathrm{kPa}$

Figure 9 Comparisons between the measured and computed results of drained shear tests at different suctions under net confining stress of $200 \mathrm{kPa}$

Figure 10 Comparisons between the measured and computed results of drained shear tests at different suctions under net confining stress of $50 \mathrm{kPa}$

Figure 11 Comparisons between computed results considering anisotropy and ignoring anisotropy of drained shear tests at different suctions under constant net confining stress of $350 \mathrm{kPa}$

Figure 12 Comparisons between the measured and computed results of anisotropic consolidation under constant net stress ratio of 0.55 and drained shear tests at different 
suctions under constant net mean stress

Figure 13 Comparisons between the measured and computed results of anisotropic consolidation under constant net stress ratio of 1.0 and drained shear tests at different suctions under constant net mean stress

Figure 14 Comparisons between computed results considering anisotropy and ignoring anisotropy of anisotropic consolidation under constant net stress ratio of 0.55 and drained shear tests at different suctions under constant net mean stress 

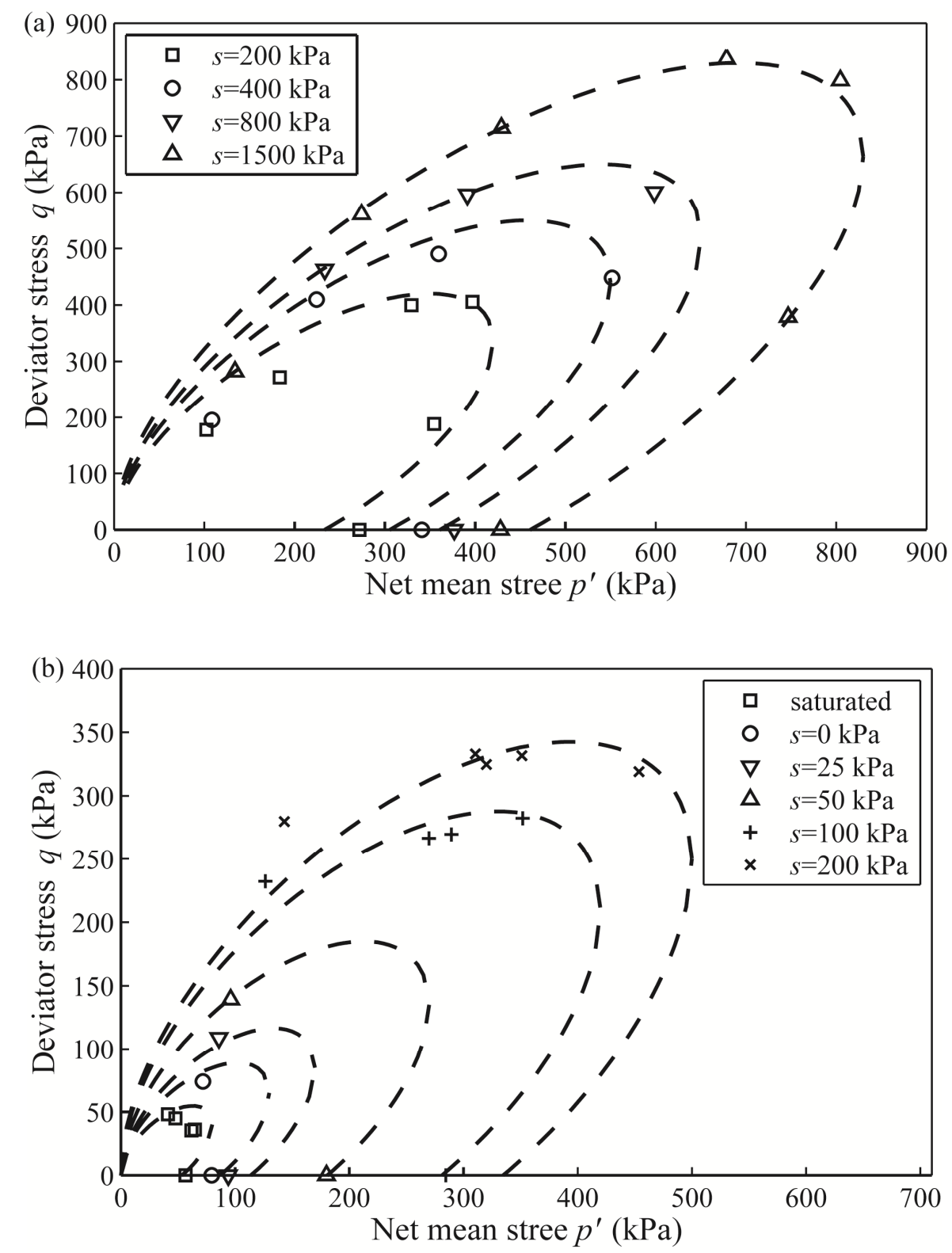

Figure 1-Yield curves based on experimental data at various suctions by (a) Cui and Delage (1996);

(b) Zhan and Ng (2006) and Chen (2007)

$8.4 \times 5.4 \mathrm{~cm}(600 \times 600 \mathrm{DPI})$ 


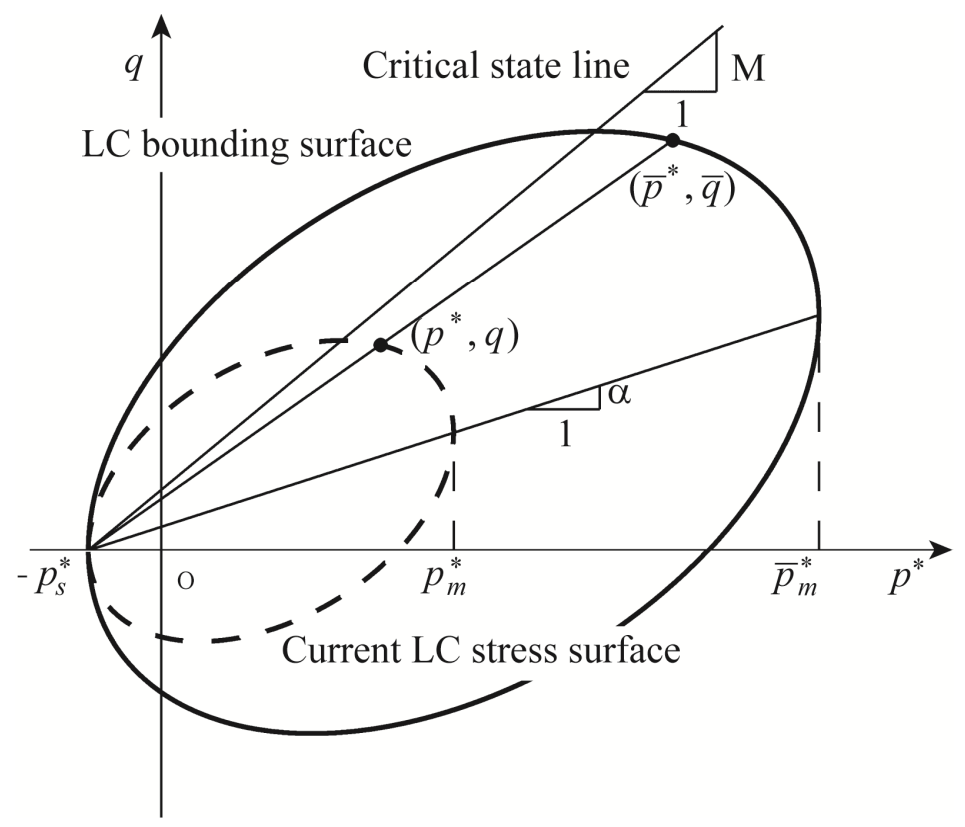

Figure 2-Illustration of anisotropic loading collapse bounding surface

$6.7 \times 5.8 \mathrm{~cm}(600 \times 600 \mathrm{DPI})$ 


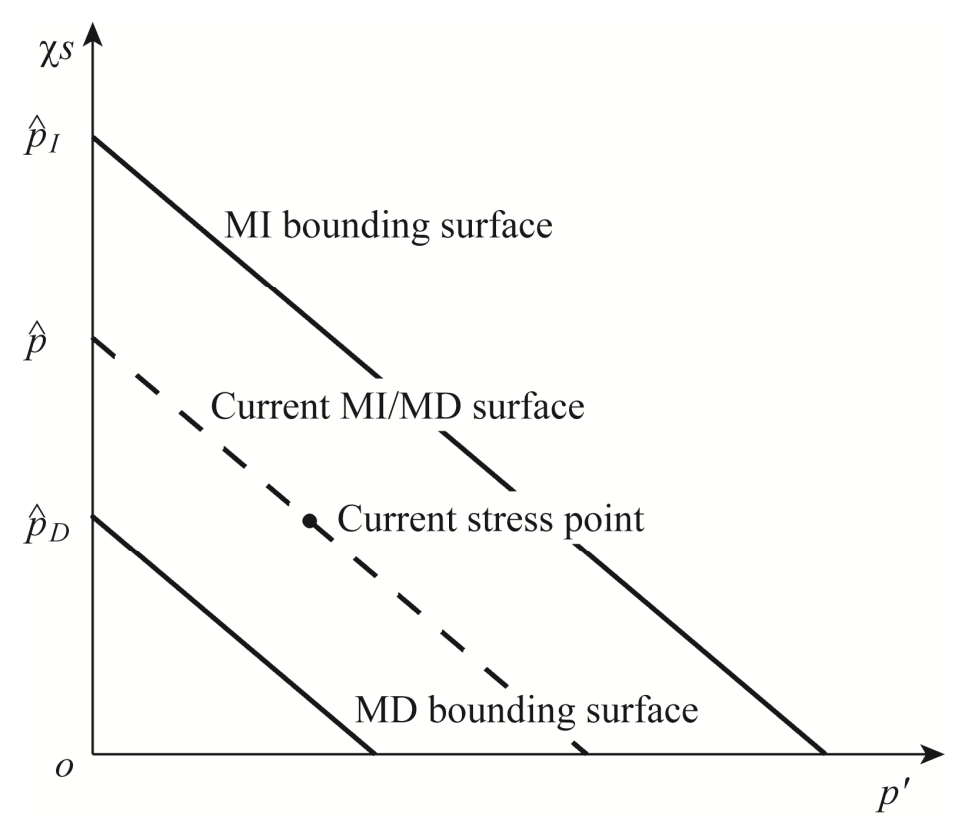

Figure 3-Illustration of MI and MD bounding surfaces $6.5 \times 5.7 \mathrm{~cm}(600 \times 600 \mathrm{DPI})$ 


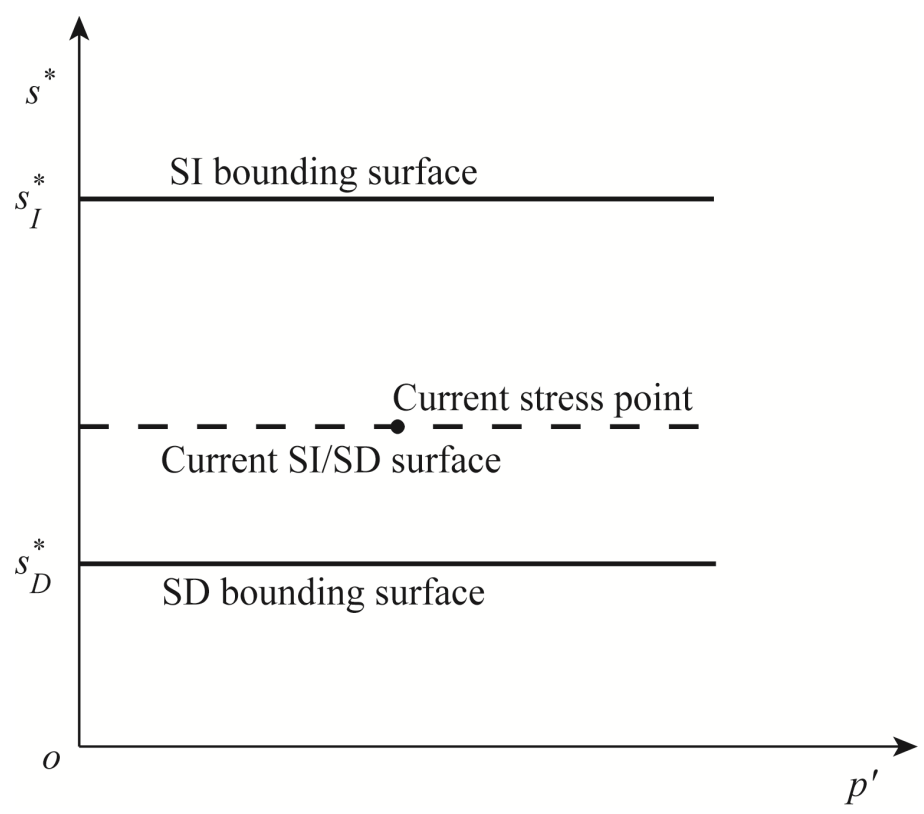

Figure 4-Illustration of SI and SD bounding surfaces

$6.5 \times 5.7 \mathrm{~cm}(600 \times 600 \mathrm{DPI})$ 


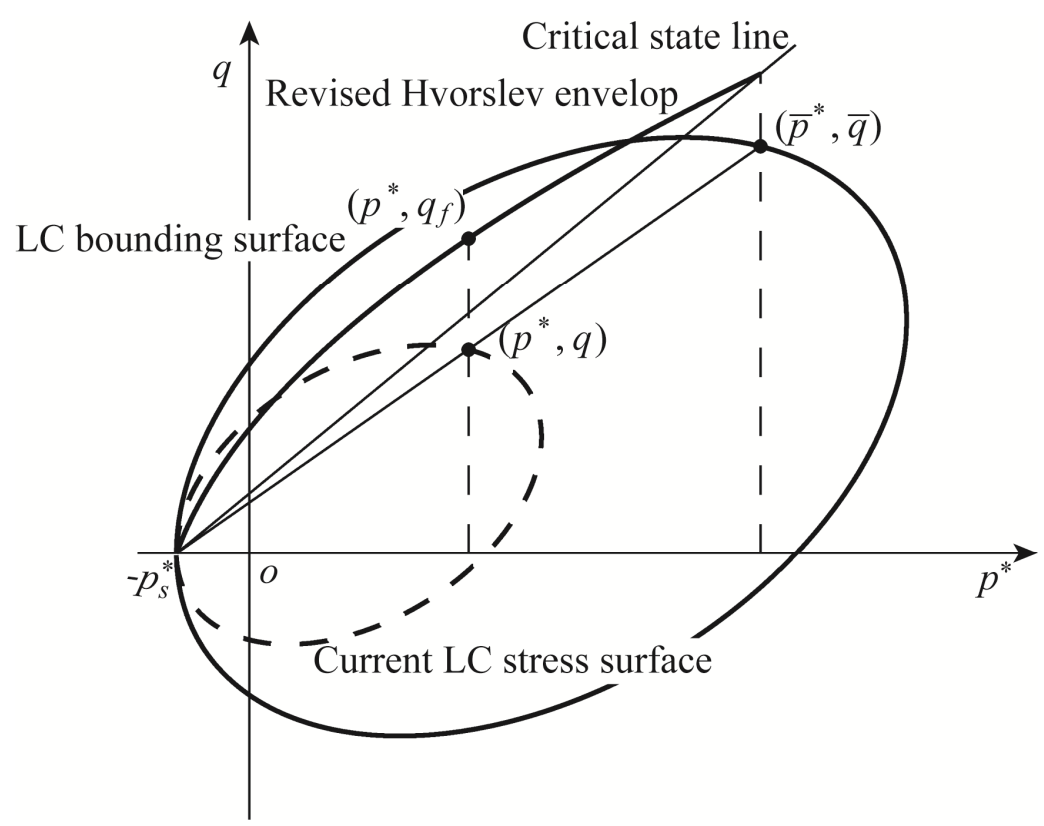

Figure 5- Illustration of the parabolic Hvorslev envelope

$7.5 \times 5.8 \mathrm{~cm}(600 \times 600 \mathrm{DPI})$ 

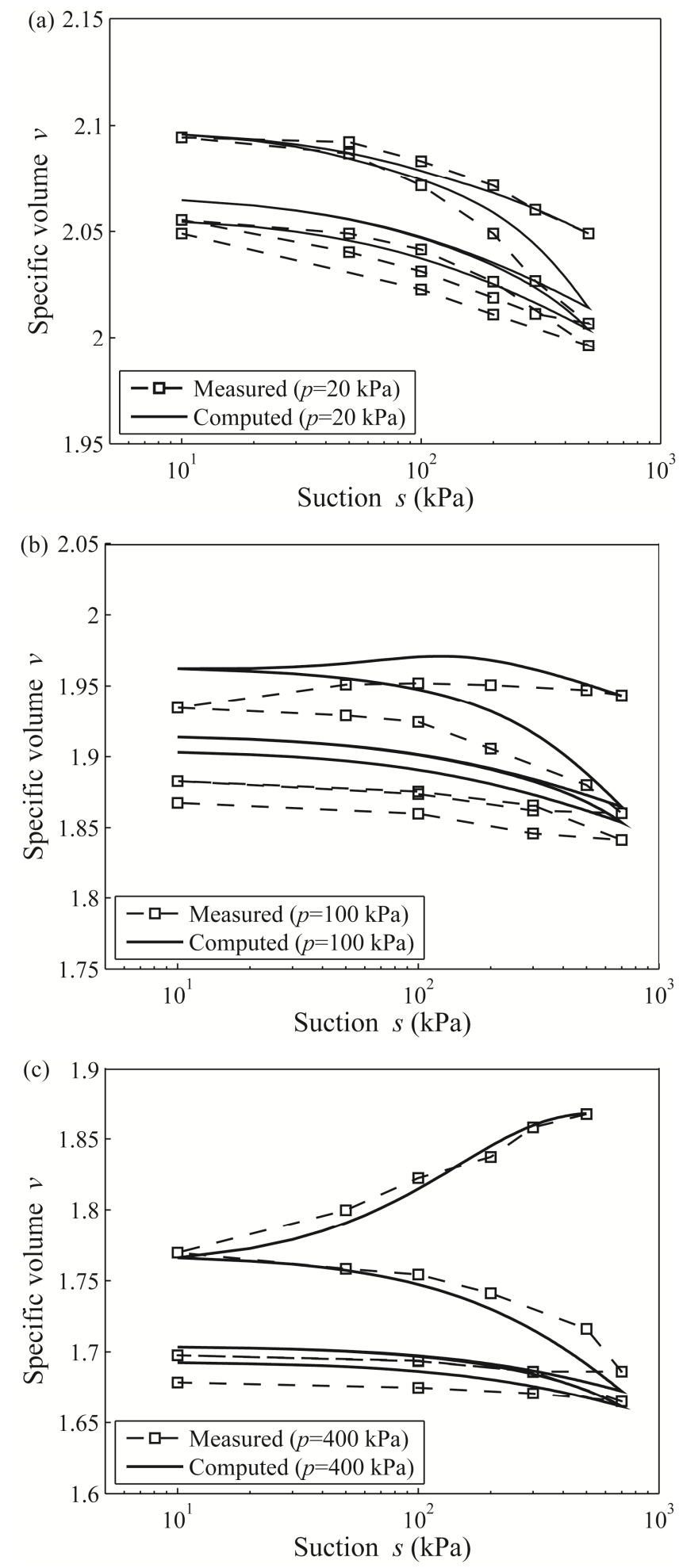

Figure 6-Comparisons between the measured and computed results of the multiple wetting and drying cycle tests for Boom Clay

\section{$8.2 \times 6.3 \mathrm{~cm}(600 \times 600 \mathrm{DPI})$}



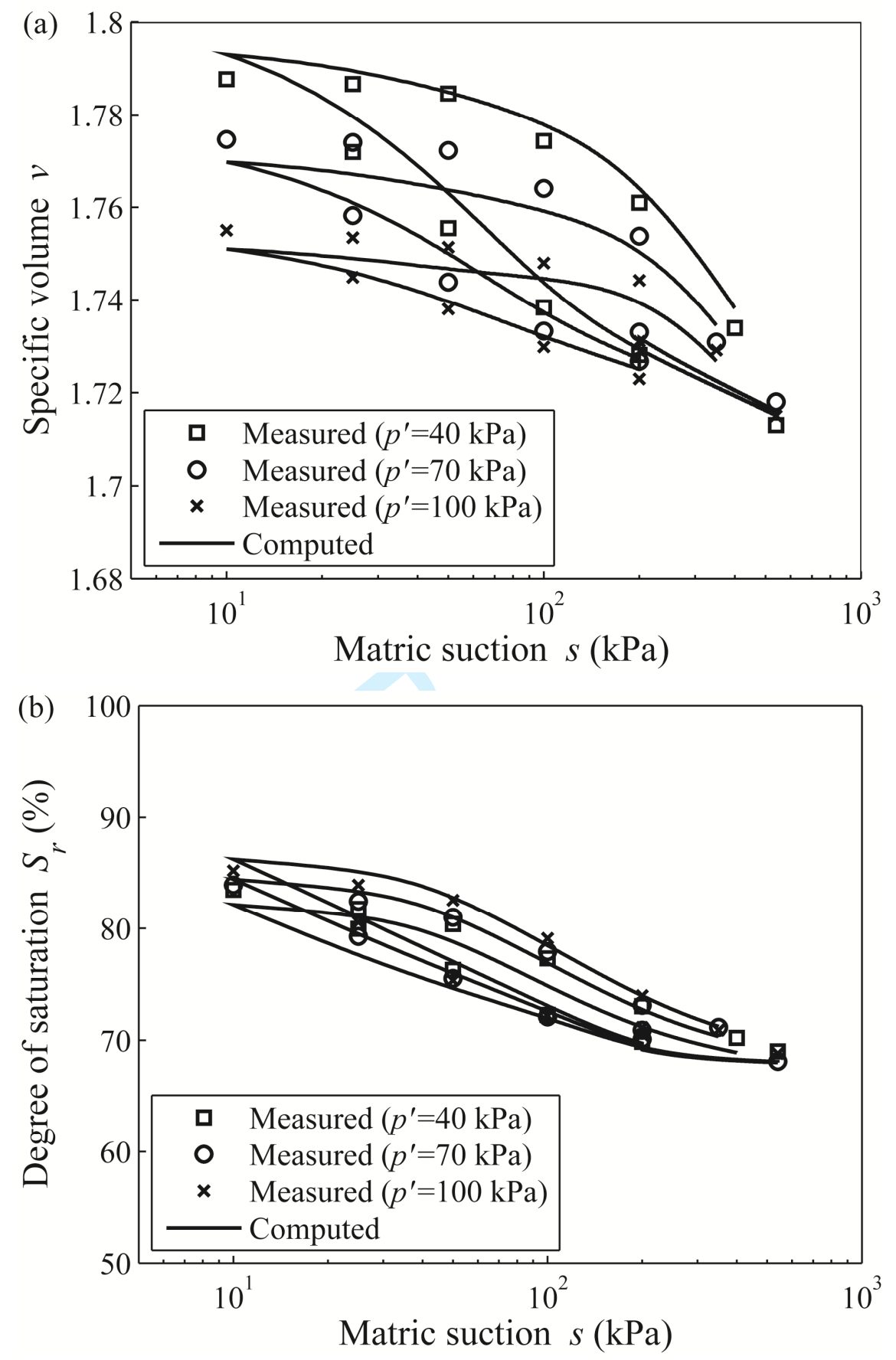

Figure 7-Comparisons between the measured and computed results of the wetting and drying cycle test for ZY expansive clay

$8.1 \times 7.0 \mathrm{~cm}(600 \times 600 \mathrm{DPI})$ 

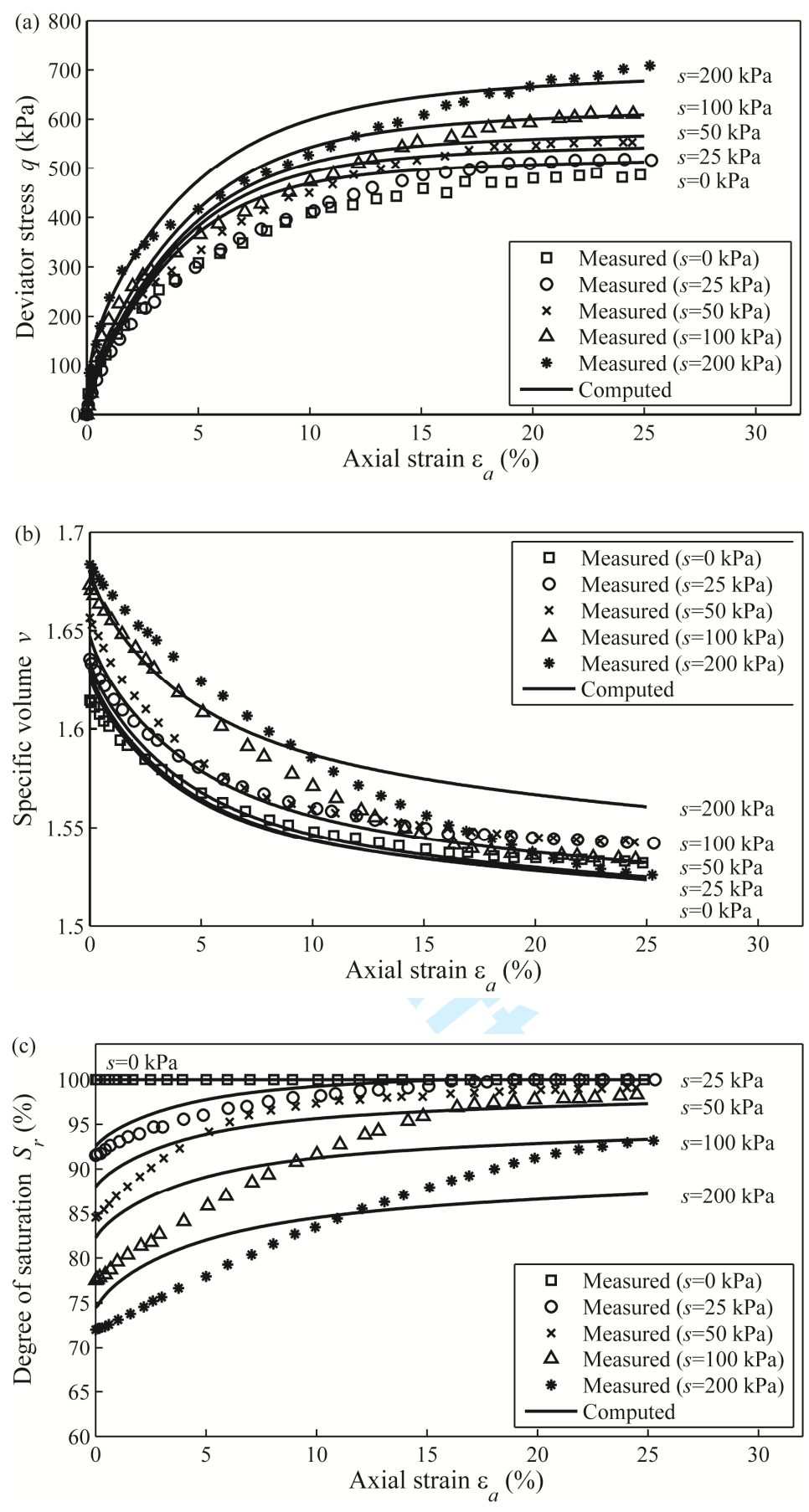

Figure 8-Comparisons between the measured and computed results of drained shear tests at different suctions under net confining stress of $350 \mathrm{kPa}$ $8.5 \times 5.1 \mathrm{~cm}(600 \times 600 \mathrm{DPI})$ 

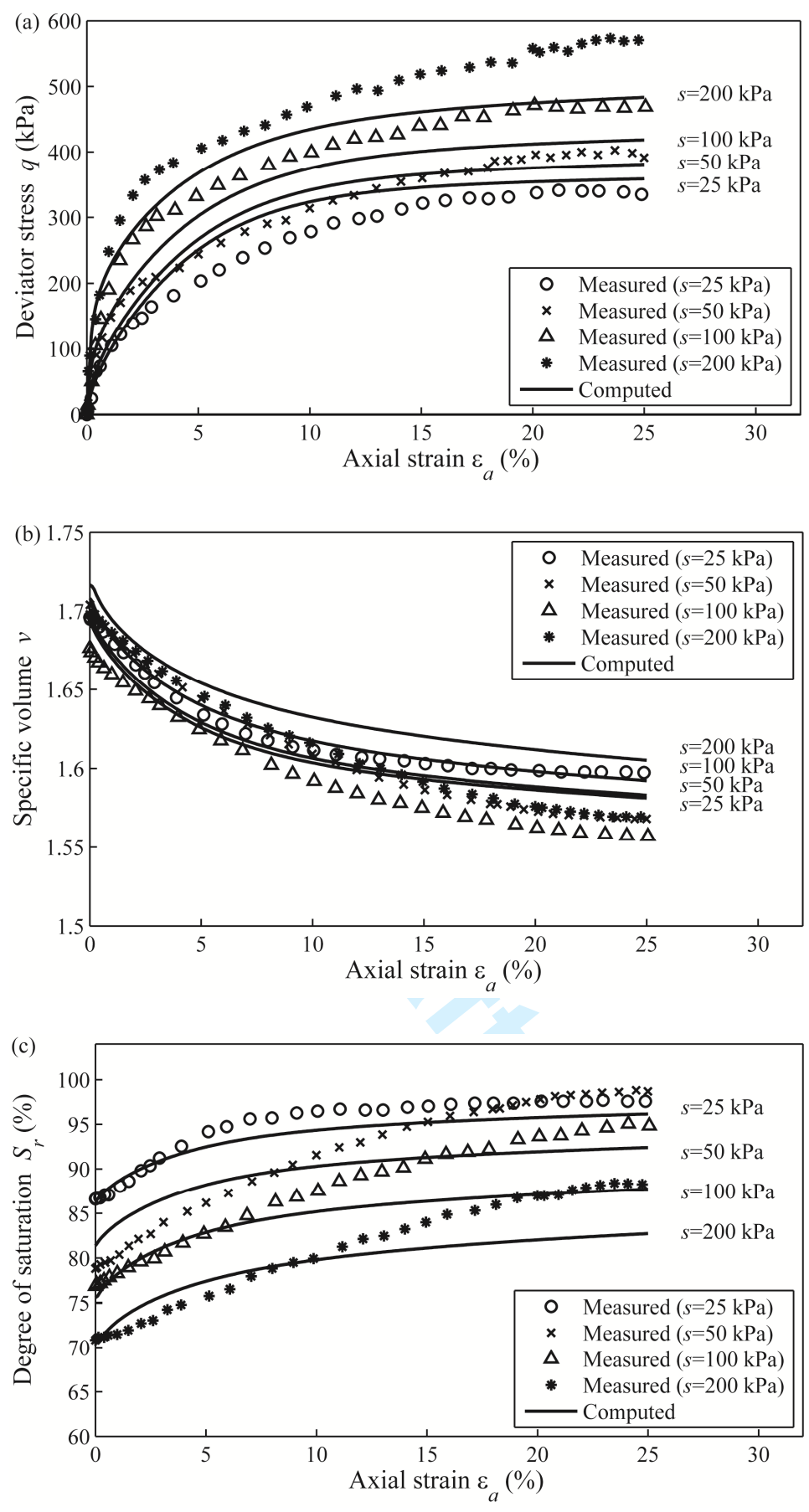

Figure 9-Comparisons between the measured and computed results of drained shear tests at different suctions under net confining stress of $200 \mathrm{kPa}$ $8.5 \times 5.1 \mathrm{~cm}(600 \times 600 \mathrm{DPI})$ 

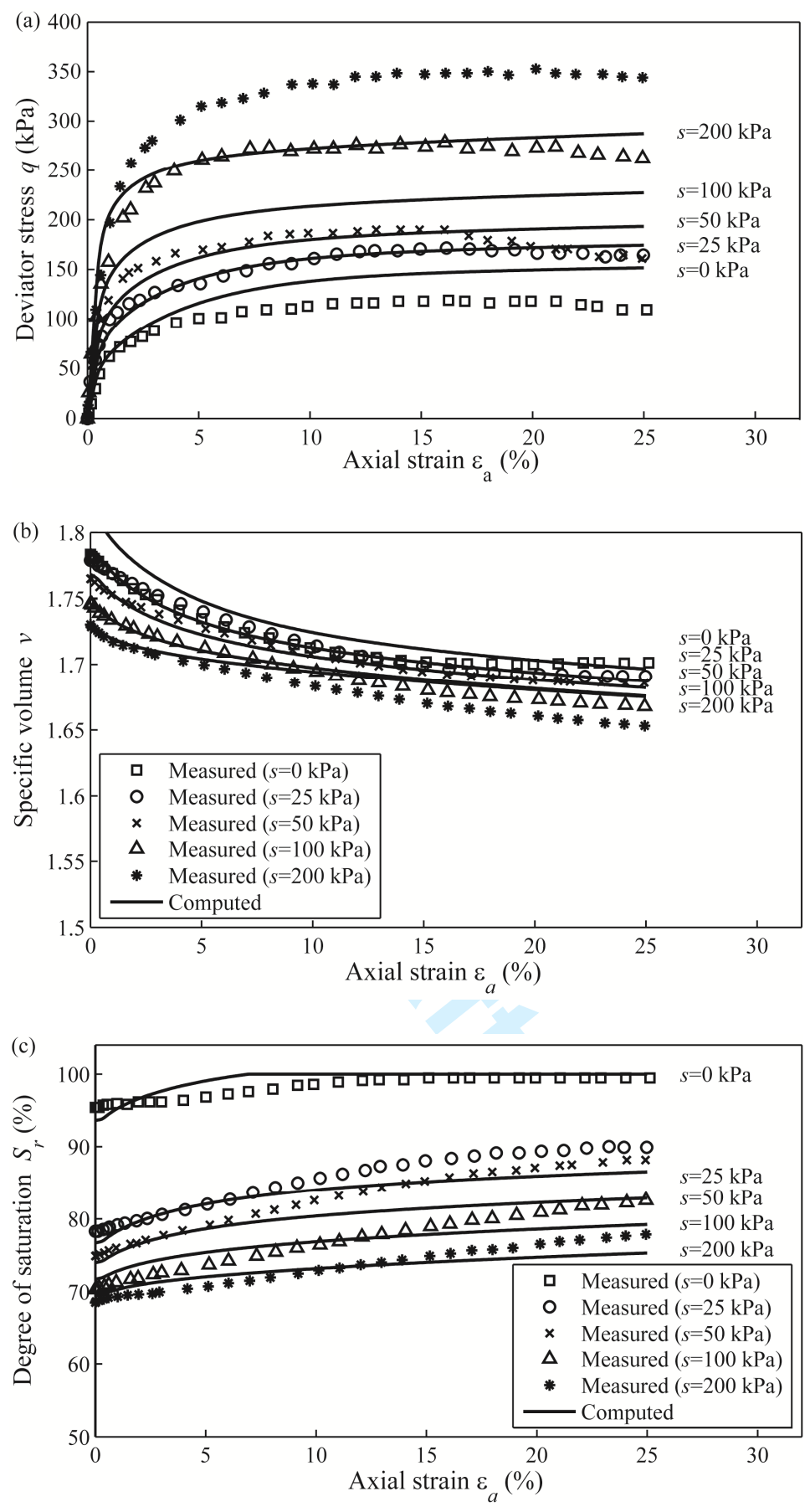

Figure 10-Comparisons between the measured and computed results of drained shear tests at different suctions under net confining stress of $50 \mathrm{kPa}$ $8.5 \times 5.1 \mathrm{~cm}(600 \times 600 \mathrm{DPI})$ 

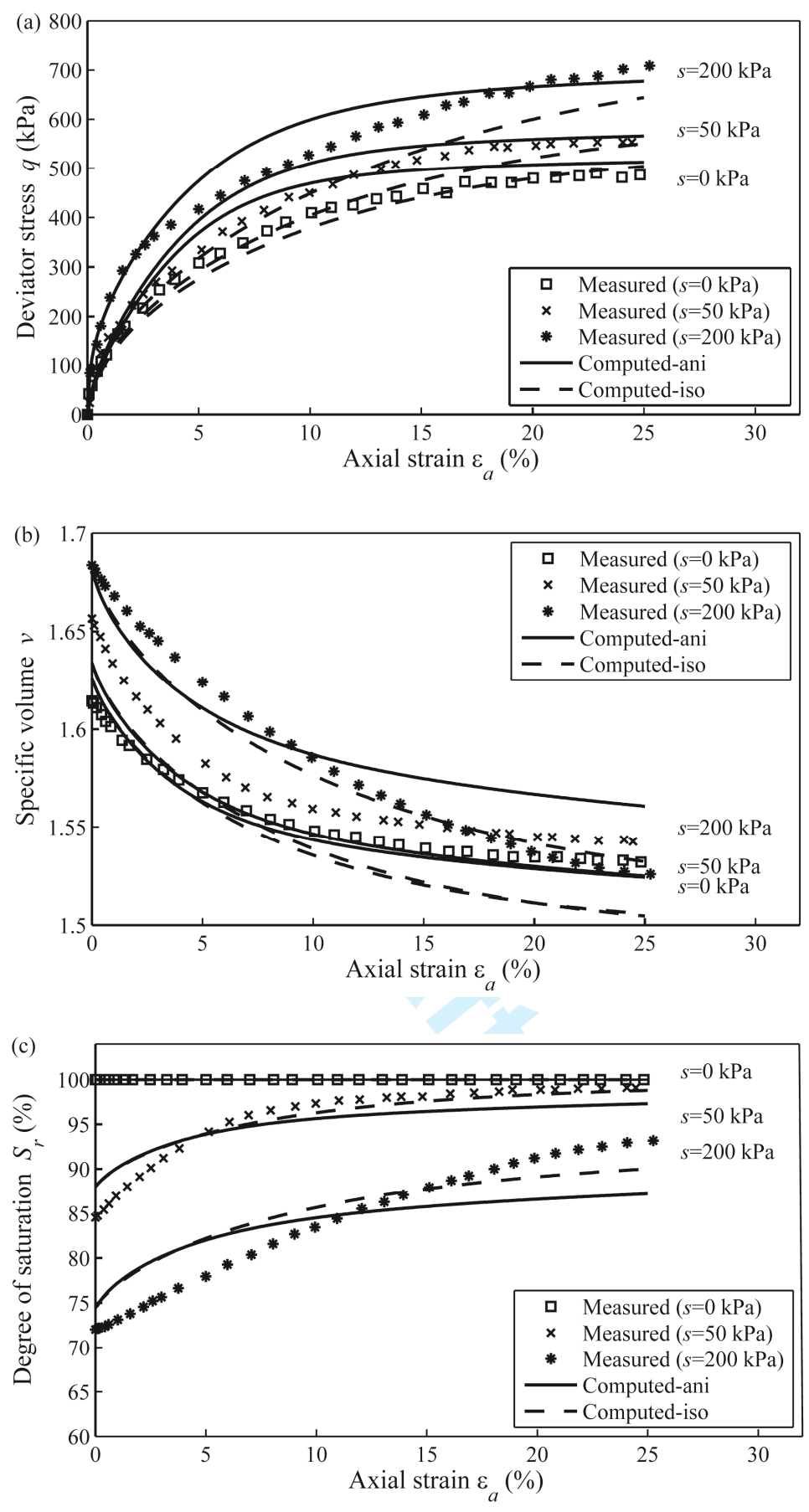

Figure 11-Comparisons between computed results considering anisotropy and ignoring anisotropy

of drained shear tests at different suctions under constant net confining stress of $350 \mathrm{kPa}$

$$
8.5 \times 5.1 \mathrm{~cm}(600 \times 600 \mathrm{DPI})
$$



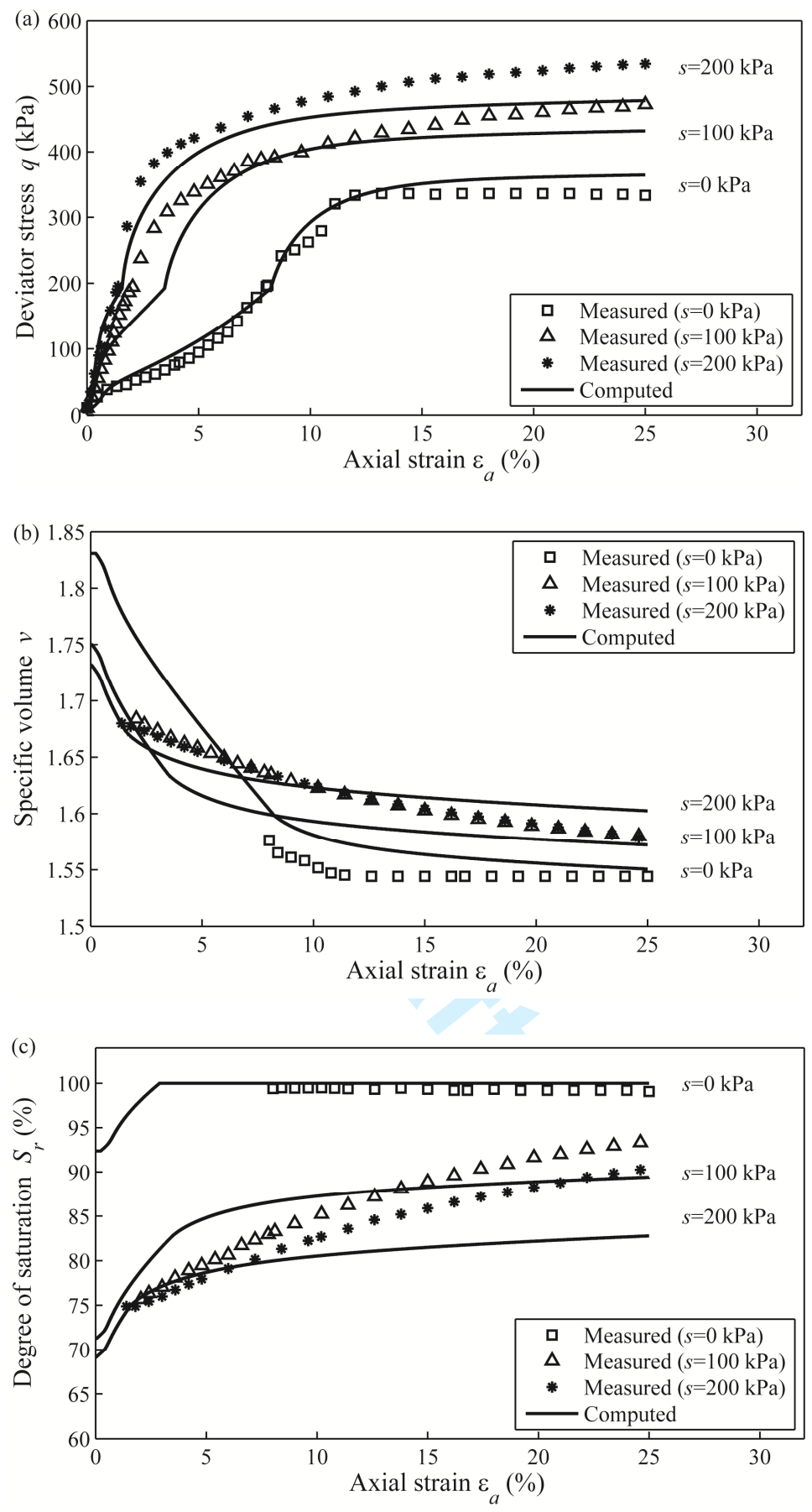

Figure 12-Comparisons between the measured and computed results of anisotropic consolidation under constant net stress ratio of 0.55 and drained shear tests at different suctions under constant net mean stress

$$
8.5 \times 5.1 \mathrm{~cm}(600 \times 600 \mathrm{DPI})
$$



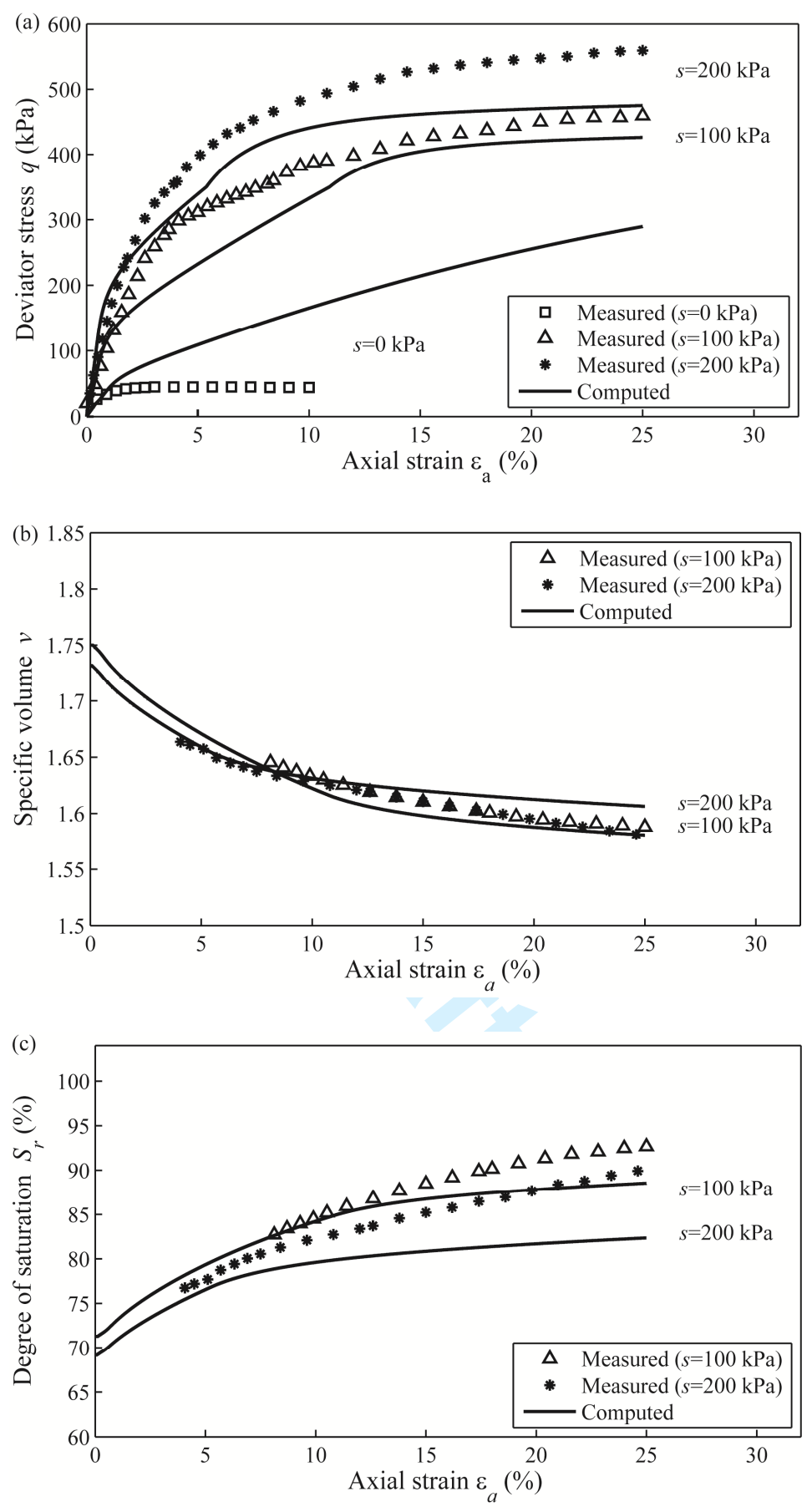

Figure 13-Comparisons between the measured and computed results of anisotropic consolidation under constant net stress ratio of 1.0 and drained shear tests at different suctions under constant net mean stress

$$
8.5 \times 5.1 \mathrm{~cm}(600 \times 600 \mathrm{DPI})
$$



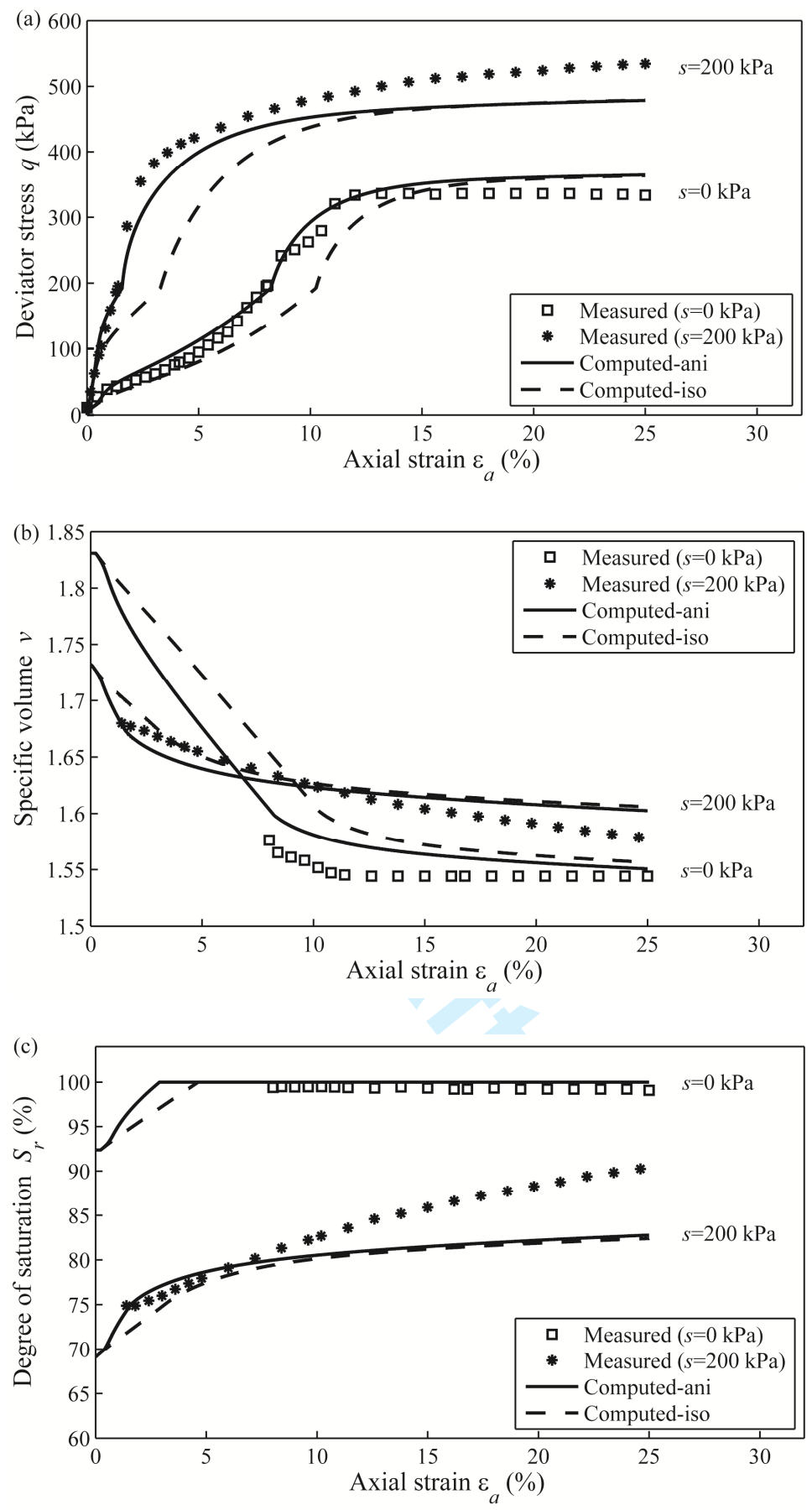

Figure 14-Comparisons between computed results considering anisotropy and ignoring anisotropy

of anisotropic consolidation under constant net stress ratio of 0.55 and drained shear tests at

different suctions under constant net mean stress

$$
8.5 \times 5.1 \mathrm{~cm}(600 \times 600 \mathrm{DPI})
$$




\section{Tables}

Table 1 Values of model parameters for Boom clay

\begin{tabular}{cccccccc}
\hline$\lambda(0)$ & $r_{\lambda}$ & $\beta_{\lambda}$ & $N(0)$ & $r_{N}$ & $\beta_{N}$ & $M$ & $\kappa$ \\
\hline 0.130 & 1.0 & 1.0 & 2.10 & 1.08 & 0.006 & 0.69 & 0.00 \\
\hline$\kappa_{m}$ & $d_{D}$ & $d_{I}$ & $\lambda_{w}$ & $\kappa_{w}$ & $k_{w s}$ & $p_{\text {ref }} / \mathrm{kPa}$ & $\gamma$ \\
\hline 0.025 & 2 & 2.0 & 0.172 & 0.02 & 0.0 & 100 & 8.0 \\
\hline
\end{tabular}

Table 2 Initial values of soil state and hardening parameters for the multiple wetting and drying cycle tests

\begin{tabular}{ccccc}
\hline$\left.e_{0}\right|_{\substack{p^{\prime}=20 \mathrm{kpa} \\
s=50 \mathrm{kpa}}}$ & $\left.e_{0}\right|_{p^{\prime}=100 \mathrm{kpa}}$ & $\left.e_{0}\right|_{\substack{p^{\prime}=400 \mathrm{kpa} \\
s=700 \mathrm{kpa}}}$ & $\left.e_{m}\right|_{\substack{p^{\prime}=20 \mathrm{kpa} \\
s=50 \mathrm{kpa}}}$ & $\left.S_{r}\right|_{s^{*}=152 \mathrm{kPa}}$ \\
\hline 2.049 & 1.943 & 1.868 & 0.426 & 0.16 \\
\hline$\left.S_{I}^{*}\right|_{s^{*}=152 \mathrm{kPa}}$ & $\left.s_{D}^{*}\right|_{s^{*}=152 \mathrm{kPa}}$ & $\hat{p}_{I} / \mathrm{kPa}$ & $\hat{p}_{D} / \mathrm{kPa}$ & \\
\hline 342 & 152 & 318 & 0 \\
\hline
\end{tabular}

Table 3 Values of model parameters for ZY expansive clay

\begin{tabular}{ccccccccc}
\hline$\lambda(0)$ & $r_{\lambda}$ & $\beta_{\lambda}$ & $N(0)$ & $r_{N}$ & $\beta_{N}$ & $M$ & $\mu / \mathrm{kPa}$ & $\kappa$ \\
\hline 0.11 & 1.45 & 0.4 & 2.27 & 1.4 & 0.2 & 0.89 & 71.2 & 0.01 \\
\hline$v$ & $\kappa_{m}$ & $d_{D}$ & $d_{I}$ & $\lambda_{w}$ & $\kappa_{w}$ & $k_{w s}$ & $p_{\text {ref }} / \mathrm{kPa}$ & $\gamma$ \\
\hline 0.3 & 0.008 & 5.4 & 3.7 & 0.13 & 0.01 & 2.0 & 0.5 & 8.0 \\
\hline
\end{tabular}


Table 4 Initial values of soil state and hardening parameters for the triaxial tests

\begin{tabular}{ccccccccc}
\hline$p^{\prime} / \mathrm{kPa}$ & $s / \mathrm{kPa}$ & $e_{0}$ & $e_{m}$ & $S_{r}$ & $s_{I}^{*} / \mathrm{kPa}$ & $s_{D}^{*} / \mathrm{kPa}$ & $\hat{p}_{I} / \mathrm{kPa}$ & $\hat{p}_{D} / \mathrm{kPa}$ \\
\hline 20 & 540 & 0.716 & 0.287 & 0.68 & 180 & 50 & 700 & 120 \\
\hline
\end{tabular}




\section{Appendix A. The alternative expression of work input}

Alternative definitions of macro void ratio and strain rates were adopted by Mašín (2013). Using these definitions, the expression of work input is deduced as follows.

The total, macro and micro structural volumetric strain rates are defined by:

(A.1) $\quad \dot{\varepsilon}_{v}=-\frac{\dot{e}}{1+e} ; \quad \dot{\varepsilon}_{v}^{M}=-\frac{\dot{e}_{M}}{1+e_{M}} ; \quad \dot{\varepsilon}_{v}^{m}=-\frac{\dot{e}_{m}}{1+e_{m}}$ where the macrostructural void ratio $e_{M}$ is defined as the ratio of macropore volume over the total volume of aggregates; the microstructural void ratio $e_{m}$ is defined as the ratio of micropore volume over the solid volume. Then the following additive equation for the void ratio $e$ hold true:

$$
e=e^{M}+e^{m}+e^{M} e^{m}
$$

Substituting Eq. (A.2) into the first equation of Eq. (A.1) leads to:

$$
\text { (A.3) } \quad \dot{\varepsilon}_{v}=\dot{\varepsilon}_{v}^{M}+\dot{\varepsilon}_{v}^{m}
$$

According to the defining of macrostructural void ratio $e_{M}$, the macroporosity $n_{M}$ and its rate could be expressed as:

(A.4) $n_{M}=\frac{e_{M}}{1+e_{M}}$

(A.5) $\quad \dot{n}_{M}=-\left(1-n_{M}\right) \dot{\varepsilon}_{M}$

Substituting Eq. (A.5) into Eq. (7) leads to:

$$
\dot{\rho}^{a g}=\frac{c^{a g}}{1-n_{M}}+\rho^{a g} \dot{\varepsilon}_{v}^{m}
$$

The mass exchange between the aggregate and the adsorbed water phases leads 
to a microstructural volume change. Thus, the micro volumetric strain rate can be expressed as:

(A.7) $\quad \dot{\varepsilon}_{v}^{m}=-\frac{\dot{V}^{a g}}{V^{a g}}=\frac{\left(c_{a g}^{a d} / \rho^{a d}\right) V}{V^{a g}}=\frac{c^{a g}}{\left(1-n_{M}\right) \rho^{a d}}$

Substituting Eqs. (6), (A.6) and (A.7) into Eq. (4) gives the work input to unsaturated expansive soils considering double porosity as:

$$
\begin{aligned}
W= & -u_{c, j}^{\prime} w_{j}^{c}-u_{a d, j}^{\prime} w_{j}^{a d}-u_{a, j}^{\prime} w_{j}^{a}+\left(\sigma_{i j}-u_{c} S_{r}^{c} \delta_{i j}-u_{a d} S_{r}^{a d} \delta_{i j}-u_{a} S_{r}^{a} \delta_{i j}\right) \dot{\varepsilon}_{i j}^{M} \\
& -n_{M}\left(u_{a}-u_{c}\right) \dot{S}_{r}^{c}-n_{M}\left(u_{a}-u_{a d}\right) \dot{S}_{r}^{a d}-\left(u_{c}-u_{a d} \frac{\rho^{c}}{\rho^{a d}}\right) \frac{c^{c}}{\rho^{c}}+u_{a} n_{M} S^{a} \frac{\dot{\rho}^{a}}{\rho^{a}} \\
& +\left(p-u_{a d}\right)\left(1-n_{M}\right) \dot{\varepsilon}_{v}^{m}+\left(p-u_{c} S_{r}^{c}-u_{a d} S_{r}^{a d}-u_{a} S_{r}^{a}\right) n_{M} \dot{\varepsilon}_{v}^{m}
\end{aligned}
$$

The new work input expression is the same as Eq. (11) except to the terms represented the work caused by the deformation of the macrostructure and microstructure. It is caused by the alternative definitions of macro and micro structural volumetric strain.

The relationships between alternative definitions and that adopted in this paper are as follows:

$$
\begin{aligned}
& \dot{\varepsilon}_{v}^{M^{\prime}}=-\frac{\dot{e}_{M}^{\prime}}{1+e}=-\frac{\dot{e}_{M}}{1+e}\left(1+e_{m}\right)-\frac{\dot{e}_{m}}{1+e} e_{M}=\dot{\varepsilon}_{v}^{M}+\dot{\varepsilon}_{v}^{m} n_{M} \\
& \dot{\varepsilon}_{v}^{m^{\prime}}=-\frac{\dot{e}_{m}^{\prime}}{1+e}=-\frac{\dot{e}_{m}}{1+e_{m}} \frac{1+e_{m}}{1+e}=\dot{\varepsilon}_{v}^{m}\left(1-n_{M}\right)
\end{aligned}
$$

The notations adopted in this paper are denoted by superscript'.

Substituting Eq. (A.9) into Eq. (A.8) leads to

$$
\begin{aligned}
W= & -u_{c, j}^{\prime} w_{j}^{c}-u_{a d, j}^{\prime} w_{j}^{a d}-u_{a, j}^{\prime} w_{j}^{a}+\left(\sigma_{i j}-u_{c} S_{r}^{c} \delta_{i j}-u_{a d} S_{r}^{a d} \delta_{i j}-u_{a} S_{r}^{a} \delta_{i j}\right) \dot{\varepsilon}_{i j}^{M^{\prime}} \\
& -n_{M}\left(u_{a}-u_{c}\right) \dot{S}_{r}^{c}-n_{M}\left(u_{a}-u_{a d}\right) \dot{S}_{r}^{a d}-\left(u_{c}-u_{a d} \frac{\rho^{c}}{\rho^{a d}}\right) \frac{c^{c}}{\rho^{c}} \\
& +u_{a} n_{M} S^{a} \frac{\dot{\rho}^{a}}{\rho^{a}}+\left(p-u_{a d}\right) \dot{\varepsilon}_{v}^{m^{\prime}}
\end{aligned}
$$

Eq. (A.10) is the same as Eq. (11). 
The work conjugated stress to $\dot{\varepsilon}_{i j}^{M}$ is $\left(\sigma_{i j}-u_{c} S_{r}^{c}-u_{a d} S_{r}^{a d}-u_{a} S_{r}^{a}\right)$ which is the same as that work conjugated stress to $\dot{\varepsilon}_{i j}^{M^{\prime}}$. However, an additional term represented the work caused by the deformation of the microstructure appears when the alternative definition of macrostructural void ratio are adopted. The additional work conjugated stress to $\dot{\varepsilon}_{v}^{m}$ is $\left(p-u_{c} S_{r}^{c}-u_{a d} S_{r}^{a d}-u_{a} S_{r}^{a}\right)$ which is the same as the stress work conjugated stress to $\dot{\varepsilon}_{v}^{M}$. The alternative definition of macrostructural void ratio has conceptual advantages (Mašín, 2013), however it complicate the work input terms caused by the deformation of the microstructure.

Besides, the alternative definition of microstructural volumetric strain doesn't lead to an addition term in the expression of work input. The new work conjugated stress to $\dot{\varepsilon}_{v}^{m}$ is $\left(1-n_{M}\right)\left(\sigma_{i j}-u_{a d}\right)$. Thus the alternative definition of microstructural volumetric strain could be chosen. 